\title{
Homologous alkyl side-chain diphosphonate inhibitors for the corrosion protection of carbon steels
}

DOI:

10.1016/j.cej.2020.126864

\section{Document Version}

Accepted author manuscript

Link to publication record in Manchester Research Explorer

\section{Citation for published version (APA):}

Moschona, A., Plesu, N., Colodrero, R. M. P., Cabeza, A., Thomas, A., \& Demadis, K. (2021). Homologous alkyl side-chain diphosphonate inhibitors for the corrosion protection of carbon steels. Chemical Engineering Journal, 405(126864). https://doi.org/10.1016/j.cej.2020.126864

\section{Published in:}

Chemical Engineering Journal

\section{Citing this paper}

Please note that where the full-text provided on Manchester Research Explorer is the Author Accepted Manuscript or Proof version this may differ from the final Published version. If citing, it is advised that you check and use the publisher's definitive version.

\section{General rights}

Copyright and moral rights for the publications made accessible in the Research Explorer are retained by the authors and/or other copyright owners and it is a condition of accessing publications that users recognise and abide by the legal requirements associated with these rights.

\section{Takedown policy}

If you believe that this document breaches copyright please refer to the University of Manchester's Takedown Procedures [http://man.ac.uk/04Y6Bo] or contact uml.scholarlycommunications@manchester.ac.uk providing relevant details, so we can investigate your claim.

\section{OPEN ACCESS}




\section{Homologous alkyl side-chain diphosphonate inhibitors for the corro- sion protection of carbon steels}

Argyri Moschona, ${ }^{1}$ Nicoleta Plesu, ${ }^{2}$ Rosario M.P. Colodrero, ${ }^{3}$ Aurelio Cabeza, ${ }^{3}$

Andrew G. Thomas, ${ }^{4 *}$ and Konstantinos D. Demadis ${ }^{1 *}$

${ }^{I}$ Crystal Engineering, Growth and Design Laboratory, Department of Chemistry, University of Crete, Voutes Campus, Heraklion, Crete, GR-71003, Greece

${ }^{2}$ Institute of Chemistry Timisoara of Romanian Academy, 300223 Timisoara, Romania

${ }^{3}$ Departamento de Química Inorgánica, Universidad de Málaga, Campus Teatinos s/n, Málaga-29071, Spain

${ }^{4}$ School of Materials and Photon Science Institute, The University of Manchester, Manchester, M13 9PL, United Kingdom

ABSTRACT: The interaction of six homologous diphosphonate additives, methylamine-N,Nbis(methylenephosphonate) (MBMP, C1-D), ethylamine-N,N-bis(methylenephosphonate) (EBMP, C2-D), butylamine-N,N-bis(methylenephosphonate) (BBMP, C4-D), hexylamine-N,Nbis(methylenephosphonate) (HBMP, C6-D), octylamine-N,N-bis(methylenephosphonate) (OBMP, C8-D), dodecylamine-N,N-bis(methylenephosphonate) (DBMP, C12-D), with carbon steel surfaces are studied by XPS at $\mathrm{pH}=3.0$. Structurally, they all possess two methylenephosphonate moieties connected to a single $\mathrm{N}$ atom. The third substituent on $\mathrm{N}$ is a non-polar, variable-length alkyl chain, $\left(\mathrm{CH}_{2}\right)_{\mathrm{x}} \mathrm{CH}_{3}$, where $\mathrm{x}=0$ (C1-D), 1 (C2-D), 3 (C4-D), 5 (C6-D), 7 (C8-D), and 11 (C12-D). XPS studies (on pristine solid diphosphonate samples and also on carbon steel specimens, immersed in aqueous solutions), indicate significant deprotonation of the diphosphonic acid molecules upon interaction with the 
metallic surface. They also prove that this surface interaction results in adsorption on the surface via the deprotonated phosphonic acid moieties. The adsorption of inhibitors on the metal surface was investigated by potentiodynamic polarization and electrochemical impedance spectroscopy. The changes detected in the charge transfer resistance $\left(\mathrm{R}_{\mathrm{ct}}\right)$ and constant phase element $(\mathrm{CPE})$ independently confirm inhibitors adsorption on metal surface. Attenuated Total Reflectance-Fourier Transform Infrared (ATRFTIR) spectroscopy and Scanning Electron Microscopy was used to investigate the nature of deposited film. Small alkyl chain diphosphonates (C1-D, C2-D and C4-D) exhibited lower corrosion resistance due to the thin, porous and/or incomplete layer formed on carbon steel surface. Longer alkyl chain molecules (C6-D, C8-D and C12-D) were found to adsorb more efficiently and form a more organized and thicker layer. The best results were obtained in the case of C8-D (lower corrosion current, higher $\mathrm{R}_{\mathrm{ct}}$ and surface coverage). In the presence of C8-D the corrosion rate was reduced by a factor of 6 .

KEYWORDS: Carbon steel, phosphonates, organic coatings, , thin films, acid corrosion, inhibition, XPS.

\section{Introduction}

Water-side carbon steel corrosion in industrial water systems has been at the epicentre of research in corrosion science [1,2]. The principal method for combating corrosion is the use of corrosion inhibitors as chemical additives, which are added into the water system on purpose in low concentrations. They protect the metallic surfaces and are categorized in two major classes, organic [3] and inorganic [4]. Corrosion protection is achieved due to inhibitor molecule aggregation or packing on the metal surface, inducing the formation of thin films. The processes responsible for this can be additive adsorption [5] or controlled precipitation, the latter occurring in synergy with metal ions in the corrosive water for example $\mathrm{Ca}^{2+}$, or $\mathrm{Mg}^{2+}[6]$. 
Phosphonic acids are phorphorus-containing organic molecules that contain one or more polar phosphonic acid groups $\left(-\mathrm{PO}_{3} \mathrm{H}_{2}\right)$ on their backbone [7]. Their choice as corrosion inhibitors is based on a number of attractive properties, outlined below:

(a) Stability towards hydrolysis and thermal decomposition [8].

(b) High affinity for the metal oxide layer [9].

(c) Dual functionality as corrosion and scale inhibitors [10].

(d) Efficiency as corrosion and scale inhibitors in a wide regime of $\mathrm{pH}$ values, due to the unique acidbase chemistry of the phosphonic acid group [11].

(e) Synergistic action with common hardness metal ions $\left(e g . \mathrm{Mg}^{2+}, \mathrm{Ca}^{2+}, \mathrm{Sr}^{2+}, \mathrm{Ba}^{2+}\right)$, thus enhancing corrosion protection [12-15].

Synthetic methodologies that have been developed through the years have given access to a wide structural variability of (poly)phosphonic acids [16]. A particular family of (poly)phosphonic acids embraces molecules that possess the zwitterionic amino-methylenephosphonate moiety, $\mathrm{N}^{+}(\mathrm{H})(\mathrm{R})\left(\mathrm{CH}_{2} \mathrm{PO}_{3} \mathrm{H}^{-}\right)\left(\mathrm{R}=\mathrm{H}\right.$, alkyl, $\left.-\mathrm{CH}_{2} \mathrm{PO}_{3} \mathrm{H}^{-}\right)$. This group can be part of a larger (poly)phosphonic acid molecule, containing one, up to five such groups. Since the focus of the present paper is on aminomethylenephosphonates that possess two phosphonate groups, we provide below a short literature overview on related molecules.

Laamari et al. evaluated the performance of the tetraphosphonate molecule HDTMP [hexamethylenediamine-N,N,N',N'-tetrakis(methylenephosphonate)] as corrosion inhibitor on carbon steel in low $\mathrm{pH}$ solutions [17]. The same corrosion inhibitor was studied by Zhao et al. on Mg implants [18]. Kavipriya et al. studied the pentaphosphonate cathodic inhibitor DTPMP (diethylenetriaminepentamethylenephosphonate) in seawater [19]. Labjar et al. found that the anticorrosion performance of the triphosphonate ATMP (aminotris-methylenephosphonate) on carbon steel in low pH solutions is controlled by physisorption [20]. Fang et al. evaluated a plethora of phosphonate additives, such as ATMP, HEDP (1-hydroxyethylidenediphosphonic acid), DMPG (N,N-dimethylidenephosphonoglycine), EEDP 
(1-ethylphosphonoethylidenediphosphonic acid), and EDTMP [ethylenediaminetetrakis(methylenephosphonic acid)], as corrosion inhibitors for carbon steel, with ATMP being the most efficient [21]. The reader is referred to a recent review discussing the chemistry of various inhibitors formulations in water systems [22].

In this paper we systematically present and discuss the interactions of several homologous aminomethylene-diphosphonates with carbon steel surfaces (studied by XPS) and their behavior as corrosion inhibitors by electrochemical and gravimetric methods. The schematic structures of these additives are shown in Figure 1. The studied diphosphonates are notated as C1-D, C2-D, C4-D, C6-D, C8-D and C12-D and contain different number of methylene units in the side-chains linked to the $\mathrm{N}$ atom. These compounds demonstrate efficient adsorption onto the carbon steel surface through the phosphonic moieties. The results of potentiodynamic polarization as well as EIS, demonstrate that the additive-induced corrosion protection is the result of the formation of a compact layer on the steel surface. The quality of the protective layer formed on metal surface depends on the diphosphonates structural features. Specifically, "longer" alkyl chain diphosphonates are predisposed to adsorb, and perhaps "pack" on the metallic surface more efficiently; yielding a more organized and thicker layer. The electrochemical measurement reveal that the corrosion resistance of carbon steel in the presence of these additives (C6-D, C8-D and C12-D) is higher and the corrosion current is lower.

\section{Experimental Section}

\subsection{Synthesis of diphosphonic acid corrosion inhibitors}

Methylamine hydrochloride, ethylamine (70\%), 1-butylamine (99\%), hexylamine (99\%), 1-octylamine (99\%), 1-dodecylamine (99\%), formaldehyde (36.5\% aqueous solution), phosphorus acid and hydrochloric acid (37\% aqueous solution) were supplied from commercial sources and used as received, without further purification. All diphosphonic acid molecules are synthesized via the Mannich-type reaction (also known as Irani-Moedritzer) according to appropriately modified published procedures 
$[23,24,25]$, see Figure 1. The detailed synthesis protocols are included in the Supplementary Information (SI). All products were isolated as high-purity $(>95 \%)$ solid acids in good yields $(>65 \%)$. Their purity and identity were confirmed by ATR-IR, ${ }^{1} \mathrm{H},{ }^{13} \mathrm{C}$, and ${ }^{31} \mathrm{P}$ NMR spectroscopy and powder X-ray diffraction measurements (see SI, Figures S1-S19).

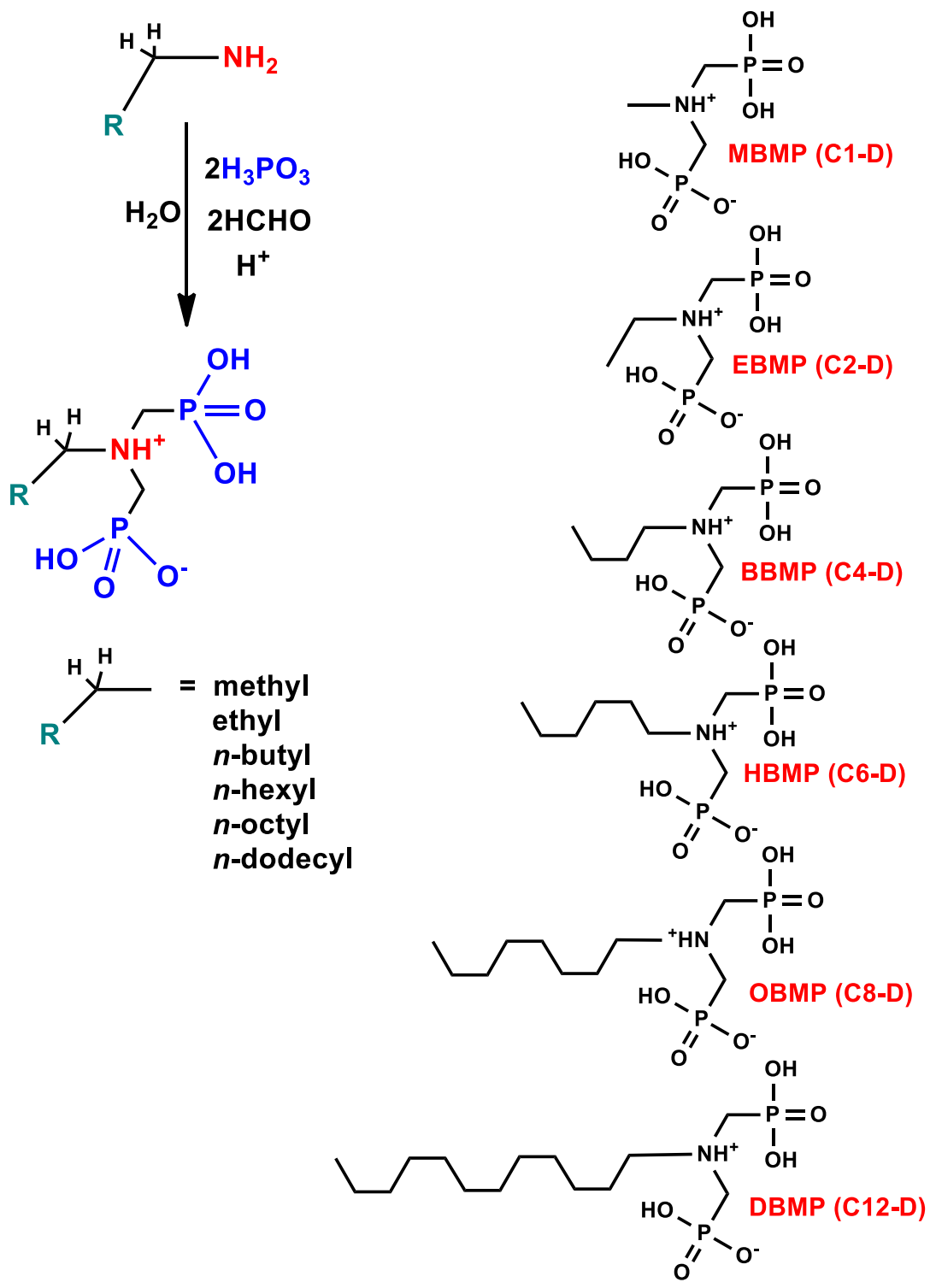

Figure 1. Synthesis procedure and schematic structures of the homologous diphosphonate corrosion inhibitors in their zwitterionic form.

\subsection{X-ray powder diffraction}

X-ray powder diffraction patterns for the structural determinations of compounds C1-D and C4-D, were collected on a D8 ADVANCE (Bruker AXS) diffractometer, in transmission configuration, equipped 
with a Johansson Ge(111) primary monochromator (Mo K $\alpha_{1}, \lambda=0.7093 \AA$ ) and a LYNXEYE XE detector. The XRPD patterns were recorded between 1.5 and $35^{\circ}(2 \theta), 0.006^{\circ}$ step size and an equivalent counting time of $768 \mathrm{~s} / \mathrm{step}$, for C1-D, and $384 \mathrm{~s} /$ step for C4-D. The structure determinations were carried out using the program EXPO2014 [26] by a simulated annealing procedure. For compound C1-D, the crystal structure of a polymorph previously described [27] was used as starting model. For solving the crystal structure of C4-D, the structure of the ligand in the solid Zn-C4-D was used as starting model. The structural models derived from direct-space approaches were optimized by the Rietveld method [28], using the program GSAS [29] and the graphic interface EXPGUI [30]. The following soft constraints were imposed in order to preserve chemically reasonable geometries for the phosphonate, amine, alkyl chain and sulfonic groups. The soft constrains were: $/ \mathrm{PO}_{3} \mathrm{C}$ tetrahedron/P-O (1.53(1) $\AA$ ), $\mathrm{P}-\mathrm{C}(1.80(1) \AA), \mathrm{O}-\mathrm{O}(2.55(2) \AA), \mathrm{O}-\mathrm{C}(2.73(2) \AA) ; / \mathrm{N}\left(\mathrm{CH}_{2}\right)_{2}$ amine group/N-C (1.50(1) $\left.\AA\right), \mathrm{C}-\mathrm{C}$ $(2.45(2) \AA), \mathrm{N}-\mathrm{P}(2.68(2) \AA), \mathrm{N}-\mathrm{C}_{\text {chain }}(2.50(2) \AA)$, /alkyl chain/C-C (1.50(1) $\left.\AA\right)$. The final weight factors for the soft constrains histograms were of 10 and 7 for ligands C1-D and C4-D, respectively. No attempts to locate the $\mathrm{H}$ atoms were carried out due to the limited quality of the XRPD data. Crystallographic details are summarized in Table S1 and the final Rietveld plots are given as Figures S20 and S21 in the SI.

\subsection{XPS}

A Kratos Axis Ultra X-ray photoelectron spectrometer, equipped with a monochromatic Al K $\alpha$ X-ray source $(\mathrm{hv}=1486.6 \mathrm{eV})$, hemispherical analyser with magnetic lens system and low energy electron source for charge compensation, was used to record the spectra. All spectra were recorded in normal emission geometry and were aligned on the binding energy scale relative to the C 1s peak at $284.8 \mathrm{eV}$. Binding energies are given with an accuracy of $\pm 0.1 \mathrm{eV}$. Survey spectra were recorded at a pass energy of $160 \mathrm{eV}$ and narrow scans at a pass energy of $20 \mathrm{eV}$. The CASA XPS software package [31] was used for peak fitting with 70:30 Gaussian Lorentzian peak shapes, unless stated otherwise. 


\subsection{Protocol for preparation of carbon steel specimens for XPS}

Powder samples were prepared by pressing the diphosphonate solids onto double-sided graphite tape. The samples were left to outgas in the load lock of the XPS chamber for 3 hours before being transferred to the photoelectron spectromemeter analysis chamber at a base pressure of $1 \times 10^{-8}$ mbar. The spectrometer used was a Kratos Axis Ultra instrument equipped with monochromated Al Ka X-ray source $(\mathrm{h} v=1486.6 \mathrm{eV})$. The built-in charge compensation source was used to remove sample charging. To investigate the interaction of the diphosphonates with carbon steel, $1.0 \times 10^{-3} \mathrm{M}$ solutions of each phosphonate were prepared in a $\mathrm{pH}=3$ phtahlate buffer containing $3.5 \% \mathrm{NaCl}$. Equivalent solutions without the presence of $\mathrm{NaCl}$ were also prepared in order to account for the presence of the buffer. In both cases $1 \mathrm{~cm}^{2}$ mild steel coupons were cut from a sheet, abraded with P240 SiC paper to remove any surface contamination and native oxide and placed in the phosphonate solutions for 24 hours. The carbon steel samples were removed from the solutions under nitrogen, via a glove box attached to the load lock of the XPS spectrometer. They were thoroughly rinsed with deionised water to prevent precipitation of excess phosphonate from solution, dried with $\mathrm{N}_{2}$ gas, attached to the sample bar using doublesided graphite tape and immediately transferred to the load lock of the XPS instrument. This was pumped down to $1.0 \times 10^{-4}$ mbar within minutes. This procedure has been shown to reduce post oxidation events of steel and iron samples, which occur if these are exposed to air [32,33,34].

\subsection{Protocol for preparation of carbon steel specimens for gravimetric studies}

Corrosion specimens (pre-treated C1010 carbon steel) were prepared and studied according to the NACE Standard TM0169-95 (Item No. 21200) with some modifications [35], which is a gravimetric method for quantifying general corrosion rates. Each steel specimen was immersed in a test solution (containing each of the disphosphonic acid). Appropriate controls (absence of inhibitor) were also tested. All experiments were performed at $\mathrm{pH} 2.0,3.0$ and 4.0 and at three different concentrations $(0.01$ 
$\mathrm{mM}, 0.10 \mathrm{mM}$ and $1.00 \mathrm{mM})$. After 7 days, the specimens were handled according to the standard NACE method to quantify corrosion rates.

\subsection{Electrochemical Measurements}

The electrochemical measurements were carried out on an Autolab 302N potentiostat/galvanostat equipped with the FRA2 impedance module, in test solutions with and without the inhibitor through a corrosion cell (Dcorr cell EcoChemie). This DCorr cell consisted of a working electrode (carbon steel specimen, exposed area $0.785 \mathrm{~cm}^{2}$ ), auxiliary electrodes (two inox electrodes) and reference electrode (Ag/AgCl electrode). At first, carbon steel was maintained in each test solution, at open circuit potential (OCP) for $1 \mathrm{~h}$ to achieve a stable state. Then, the electrochemical impedance spectroscopy (EIS) experiments were performed at OCP in frequency range $0.01 \mathrm{~Hz}$ to $100 \mathrm{kHz}$, with $10 \mathrm{mV}$ sinusoidal potential amplitude. ZView (Scribner Associated Inc.) software was used to model the experimental data. Finally, the potentiodynamic polarization curves were recorded and potential was swept from $+200 \mathrm{mV}$ to $1200 \mathrm{mV}$ at a scan rate of $1 \mathrm{mV} \cdot \mathrm{s}^{-1}$. A $3.5 \% \mathrm{NaCl}$ solution (pH 3.0), was used as an electrolyte in studies of corrosion inhibitors, served as a blank solution (control) in electrochemical measurements. All measurements were carried out at room temperature. The test solutions contain $4.6 \mathrm{mM}$ diphosphonic acid. The $\mathrm{pH}$ of test solutions was readjusted to $\sim 3$, with $\mathrm{NaOH}$. All tests of the same conditions were performed three times to obtain good reproducible results.

\subsection{Vibrational Spectroscopy}

Attenuated Total Reflectance Infrared (ATR-IR) spectra were recorded with a FT/IR-4200 JASCO Spectrophotometer, equipped with PIKe ATR (MIRacle), DTGS detector, Ge crystal plate. Resolution

was set at $4 \mathrm{~cm}^{-1}$, and the scan range was $4000-600 \mathrm{~cm}^{-1}$. The Spectral Manager Version 2 software was used to analyze the data.

\section{Results and Discussion}




\subsection{Crystal structures of C1-D and C4-D diphosphonic acids}

The crystal structure of both amino-bis(methylenephosphonic acids), C1-D and C4-D, has been solved by direct-space approach and refined by the Rietveld method. Views of their structures are shown in Figure 2. Both phosphonic acids have two phosphonate groups per formula unit, which are crystallographically and chemically non-equivalent. Although hydrogen atoms could not be localized, these ligands usually appear in zwitterionic forms with the highly basic $\mathrm{N}$ atom of the amino group being protonated and one the two phosphonic acid groups being singly deprotonated. This is a common phenomenon in these aminomethylenephosphonate molecules $[36,37,38]$. It is interesting to note that the synthesis procedure followed for the compound C1-D has led to the preparation of a new crystal polymorph. In contrast with the monoclinic phase previously reported [27], C1-D crystallizes in the orthorhombic system, with a unit cell parameters similar to the reported for the ligand C2-D (a=8.711(2) $\AA$, $\mathrm{b}=$ 12.312(5) $\AA, c=8.763(8) \AA, Z=4$, space group P 2 $\left.{ }_{1}{ }_{1} 2_{1}\right)[39]$.

Figure 2 shows the molecular structures and crystal packing of compounds C1-D and C4-D. The 3-D supramolecular arrangement of these diphosphonic acids, results from the formation of hydrogen bonds between the phosphonic groups of adjacent molecules. In the case of C4-D, the molecules are arranged in interdigitated molecular layers, with the phosphonic groups from adjacent molecules facing each other and interacting via hydrogen bonding creating a polar region (Table S2 in the SI). The interaction between the alkyl chains is only through van der Waals forces. As it is common for this class of compounds, hydrogen bonding interactions between the $-\mathrm{NH}^{+}$and $\mathrm{O}$ moieties of the phosphonate groups are also present. 
(a)
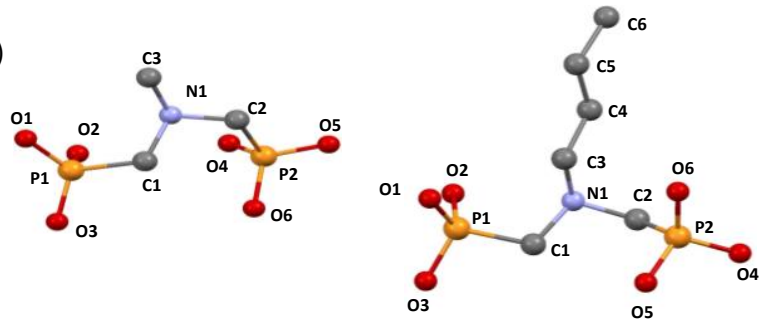

(b)
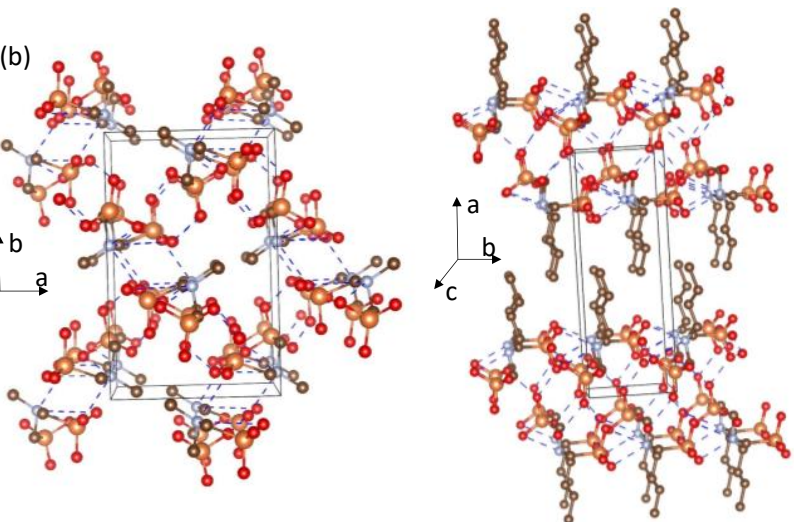

Figure 2. (a) Molecular structure of C1-D (left) and C4-D (right) and (b) view of the packing with Hbonds marked in blue. Color codes: $\mathrm{O}$ red, $\mathrm{P}$ orange, $\mathrm{C}$ grey, $\mathrm{N}$ blue.

Figure 2a (left) shows the molecular structure of compound C1-D and the packing of the molecules in the crystal lattice. The 3-D supramolecular arrangement results from the formation of hydrogen bonds between the phosphonic groups of adjacent molecules in a similar way that the described for compound C2-D. In addition, $\mathrm{N} \cdot \mathrm{O}$ intra- and intermolecular hydrogen bonds participate in the stabilization of the crystal structure (Table S2 in the SI).

Compound C4-D crystallizes in the monoclinic system, space group P $2{ }_{1}$. Figure $2 \mathrm{~b}$ (right) displays the content of the asymmetric part of the unit cell and the supramolecular assembly. The C4-D molecules arranged in interdigitated molecular layers, as observed for benzylamino-N,N-bis methylphosphonic acid [37], with the phosphonic groups from adjacent molecules facing each other and interacting via hydrogen bonding creating a polar region (Table S2 in the SI). The interaction between the alkyl chains is only through van der Waals forces. As it is common for this class of compounds, hydrogen bonding interactions between the $-\mathrm{NH}^{+}$and $\mathrm{O}$ moieties of the phosphonate groups are also present. 


\subsection{XPS studies}

XPS spectra were recorded from the powders and steel coupons following immersion in buffered phosphonate and buffered phosphonate $/ \mathrm{NaCl}$ in order to investigate the surface chemistry of the steels with and without the inhibitors. Survey spectra from the coupons are shown in Figure S22.

The N 1s spectra in Figure 3a recorded on pristine inhibitor powders show a dominant peak at a binding energy of $401.9 \mathrm{eV}$. This is consistent with the presence of protonated tertiary amine groups, in agreement with our previous work on tetraphosphonates [40]. The protonation occurs via transfer of a proton from the acidic phosphonate group. In contrast to the tetraphosphonates we see little evidence of the deprotonated amine at $399.4 \mathrm{eV}$ for the powders except in the C12-D compound.

Equivalent spectra for the steel coupons immersed in the buffered $\mathrm{NaCl}$ solution are shown in Figure 3b. Two N 1s peaks are evident for all diphosphonates at binding energies of $402.0 \mathrm{eV}$ and 399.7 $\mathrm{eV}$, consistent with the presence of protonated and non-protonated amine. The same effect is observed for the non-salinated buffer solution as shown in Figure S23 in the SI. However, we note that the nonprotonated amine is dominant, following adsorption from solution for all compounds [40]. Unlike our previous work on the tetraphosphonates, however, all samples seem to have the majority of the phosphonate present at the steel surface in the deprotonated form and, in fact, inhibitors C8-D and C12-D appear to have the amine fully non-protonated. 

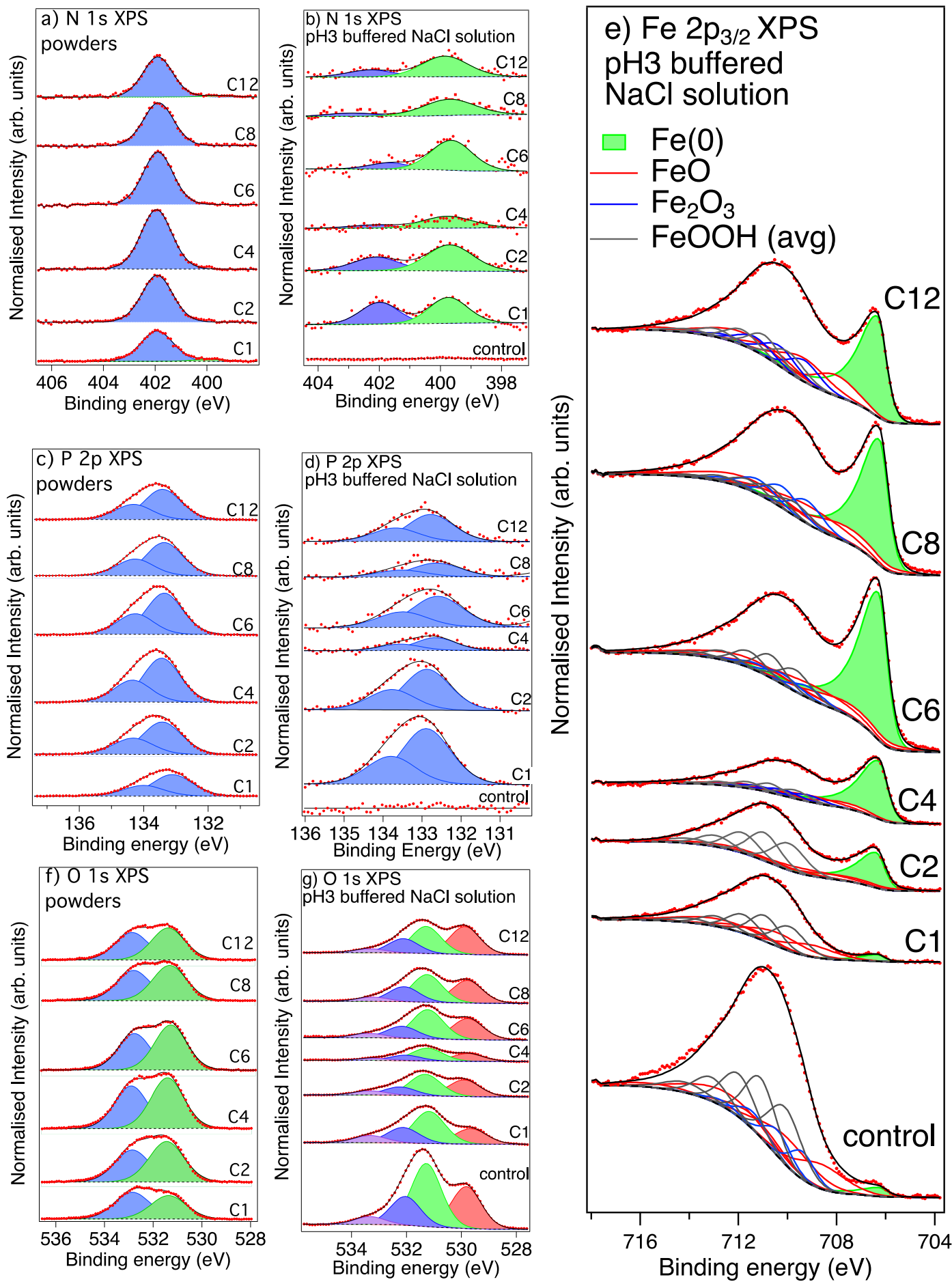

Figure 3. XPS spectra recorded from N1s from (a) powders, (b) steel coupons immersed in $1 \mathrm{mM}$ solutions of inhibitors in $3.5 \% \mathrm{NaCl}$ solution at $\mathrm{pH}=3 . \mathrm{P} 2 \mathrm{p}$ spectra from (c) powders and (d) from the steel coupons after immersion. (e) Fe $2 \mathrm{p}_{3 / 2}$ spectra from the coupons. $\mathrm{O} 1 \mathrm{~s}$ from (f) powders and (g) steel coupons after immersion. 
The P 2p spectra in Figures 3c for the C2-D, C4-D, C6-D, C8-D and C12-D powders can all be fitted with a spin-orbit split doublet at binding energies of 133.4 and $134.3 \mathrm{eV}$, corresponding to emission from the $\mathrm{P} 2 \mathrm{p}_{3 / 2}$ and $\mathrm{P} 2 \mathrm{p}_{1 / 2}$ states of the phosphonate group [42], respectively. The $\mathrm{P} 2 \mathrm{p}$ peaks for the C1-D powder are at slightly lower binding energies, 133.1 and $134.0 \mathrm{eV}$. The reason for this difference is unclear, but most likely arises from some differential charging which is not compensated for in the binding energy alignment for this sample. The shift, however, may also be associated with partial deprotonation of the phosphonic acid group $[42,43]$.

Following adsorption on the steel coupons from the buffered with $\mathrm{NaCl}$ and buffered without $\mathrm{NaCl}$ solutions (Figures $3 \mathrm{~d}$ and $\mathrm{S} 23$, in the $\mathrm{SI}$ ) the binding energy of the $\mathrm{P} 2 \mathrm{p}$ is shifted downwards to give peaks at 132.7 and $133.6 \mathrm{eV}$. This downward shift is consistent with our previous observations for tetraphosphonates [40]. This shift of the dominant doublet in the P $2 p$ spectra indicates deprotonation of the phosphonate group [42], suggesting adsorption to the steel via the phosphonate group [43]. There is no evidence of the protonated phosphonate (observed for the diphosphonate pure powders), which would seem to indicate that adsorption to the steel surface occurs via both phosphonate groups. The same behavior is observed for the coupons immersed in buffer without $\mathrm{NaCl}$ (Figure $\mathrm{S} 23$ in the SI) suggesting that at $\mathrm{pH}=3$, adsorption via the phosphonate is preferred, regardless of $\mathrm{NaCl}$ content.

The Fe $2 p$ spectra shown in Figure $3 e$ show the presence of metallic iron and some oxidation products. The metallic peak is fitted with an asymmetric Lorentzian curve to account for excitation of conduction electrons (green colored peak) [44]. The oxide-related features are fitted with multiplet structures according to the work of Biesinger et al. [45]. Although these multiplet structures, due to the interaction of the outgoing $2 \mathrm{p}$ electron, and the residual core hole with the d-electrons in the valence band, make the fitting of iron oxides difficult, they allow identification of three oxidized species: FeO, $\mathrm{Fe}_{2} \mathrm{O}_{3}$ and $\mathrm{Fe}(\mathrm{OOH})_{\mathrm{x}}$. The latter is fitted with an average multiplet structure $[45,46]$. Table 1 shows the relative proportions of the various iron components present in the buffered and buffered/ $\mathrm{NaCl}$ samples. For the samples immersed in $\mathrm{pH}=3.0$ buffered solution (Figure $\mathrm{S} 23$ ) it is clear that the predominant oxide phase is $\mathrm{FeO}$ with small amounts of $\mathrm{Fe}(\mathrm{III})$ and oxy-hydroxides. 
Table 1. Composition of iron species at the surface of the sample from the $\mathrm{NaCl}$ solutions at $\mathrm{pH}=3.0$. Numbers in brackets are the equivalent values for the buffer without $\mathrm{NaCl}$. All figures quoted are \pm 0.5 $\%$.

\begin{tabular}{lllll}
\hline Inhibitor & $\mathrm{Fe}^{0}$ & $\mathbf{F e O}$ & $\gamma-\mathrm{Fe}_{2} \mathrm{O}_{3}$ & $\mathbf{F e O O H}$ \\
\hline C1-D & $4.5(48.4)$ & $51.9(40.7)$ & $0(9.8)$ & $43.7(1.1)$ \\
C2-D & $24.9(41.1)$ & $29.5(51.5)$ & $0(4.0)$ & $45.6(3.4)$ \\
C4-D & $48.4(42.8)$ & $27.2(46.0)$ & $10.6(6.6)$ & $13.8(4.6)$ \\
C6-D & $45.8(45.0)$ & $32.5(47.3)$ & $7.0(4.4)$ & $14.8(3.4)$ \\
C8-D & $39.0(45.5)$ & $36.3(46.9)$ & $14.2(4.8)$ & $10.1(5.2)$ \\
C12-D & $35.0(49.1)$ & $34.0(43.3)$ & $14.8(0)$ & $16.2(7.6)$ \\
Buffer (control) & $2.8(4.8)$ & $41.9(46.7)$ & $13.7(9.0)$ & $41.7(0.7)$ \\
\hline
\end{tabular}

In contrast, the samples immersed in buffered saline solution show a marked difference in the amount of metallic iron present, depending upon the side-chain length of the diphosphonates. For the control solution and the C1-D and C2-D diphosphonates only a small amount of metallic Fe is found to be present at the surface. For C4-D the highest metallic Fe component is noted, with a similar amount for the C6-D compound. For C12-D the amount of metallic iron seems to decrease. This would seem to be in agreement with the corrosion measurements presented below, where the C4-D compound shows the highest inhibition, with C6-D being the next most effective. C12-D seems to be an exception to this observation since the corrosion measurements show increased corrosion rate but the XPS still shows a reasonable amount of metallic iron.

$\mathrm{O} 1 \mathrm{~s}$ spectra are shown in Figure $3 \mathrm{f}$ (powders) and Figure $3 \mathrm{~g}$ (steel specimens in $\mathrm{pH}=3.0 \mathrm{NaCl}$ + phosphonate). Diphosphonic acid powders exhibit two peaks at binding energies of 531.4 and 532.9 $\mathrm{eV}$, of roughly equal intensity. These are indicative of the presence of $\mathrm{P}=\mathrm{O}$ and $\mathrm{P}-\mathrm{OH}$ moieties, respectively. One would expect a 2:1 ratio of these peaks for the pure compounds, if no deprotonation has occurred. However, the N 1s spectra for the powder suggest that there is some intramolecular proton trans- 
fer from the phosphonic acid to the amine group. It should be noted that there is also likely to be some contribution from adsorbed atmospheric hydrocarbons in the $\mathrm{O} 1 \mathrm{~s}$ spectra $[47,48]$.

For the steel coupons immersed in $3.5 \% \mathrm{NaCl}$ at $\mathrm{pH}=3$, additional peaks are observed at 529.9 $\mathrm{eV}$, from the metal oxide, and $533.8 \mathrm{eV}$ which may be due to residual adsorbed water or the phthalate buffer. It is also clear that the peak from the phosphonate arising from $\mathrm{P}-\mathrm{OH}$ has decreased in intensity relative to the $\mathrm{P}=\mathrm{O}$ derived feature. This provides further evidence that the phosphonate becomes deprotonated upon adsorption on the metal/metal oxide surface. The data for the solutions without salt show very little difference to those with $\mathrm{NaCl}$.

In summary, the XPS data suggest that the diphosphonates adsorb onto the steel coupons through the phosphonate group oxygens but that this adsorption is on the Fe surface rather than the oxide This may suggest that the inhibitors work by slowing the formation of soluble oxides at the surface of the Fe by forming a monolayer type barrier at the surface of the coupons.

\subsection{Corrosion inhibition (gravimetric)}

All diphosphonic acids were tested at three $\mathrm{pH}$ values, ie. 2.0, 3.0 (same as the XPS measurements), and 4.0, and at concentrations $0.01 \mathrm{mM}, 0.10 \mathrm{mM}$, and $1.00 \mathrm{mM}$. Visual inspection of the "control" specimen (no inhibitors) after air-drying, showed general corrosion on the specimen surface. In contrast, the steel revealed a protective coating on the surface when the diphosphonates were present. Figure S24 in the SI shows all specimens for comparison.

The carbon steel surfaces exposed to $\mathrm{pH}=3$ were further studied in detail, since the XPS experiments were carried out at that $\mathrm{pH}$. Figure S25 shows the steel surfaces at a higher magnification, clearly showing the dramatic differences between the control and the disphosphonate-protected surfaces. Notably, the inhibitor concentration was $4.6 \mathrm{mM}$ (compared to the lower concentrations used to obtain the images in Figure S24). This is why the specimens in Figure S25 appear more protected. 
The optical images of the carbon steel surfaces after immersion (in the absence or presence of inhibitors, Figure S25) warrant some discussion. The metal surface was substantially covered by corrosion products in the case of the "control". There were minor corrosion products present on the carbon steel surface in the case of C12-D inhibitor (Figure S25). Comparing the images of samples with and without inhibitor, it is obvious that a protective layer was formed in the presence of inhibitors on the metal surface. Considering that the interaction between the phosphate group and the iron substrate is favorable, it is expected that the adsorbed inhibitor layer is capable of displacing $\mathrm{H}_{2} \mathrm{O}$ molecules from the iron surface. The hydrophobic alkyl chains of the adsorbed inhibitor molecules transform the metallic surface from a hydrophilic to a hydrophobic one, which is beneficial for corrosion protection. The film formed in the presence of C1-D, C2-D looks thinner than that the one formed in the presence of C6-D and C8-D. In the presence of C4-D and C12-D the film seems to be more porous. The best coverage and protection are observed in the case of C8-D.

In addition to these qualitative visual observations, corrosion rates were calculated based on mass loss measurements (see Section 2.5 above). The results are presented in Table S3. Corrosion inhibition efficiencies (\%) were also calculated and presented in a graphical form, in Figure 4. In general, all diphosphonates show poor inhibition efficiencies at $\mathrm{pH}=2$, except $\mathrm{C} 8$-D, which shows efficiencies of $\sim$ $25 \%$ (at $0.10 \mathrm{mM}$ and $1.00 \mathrm{mM}$ concentrations). At the $\mathrm{pH}$ of 3, C4-D shows medium efficiency of $24 \%$ and $\mathrm{C} 8$-D of $\sim 29 \%$. Finally, at $\mathrm{pH}=4, \mathrm{C} 1-\mathrm{D}$ reaches a $\sim 84 \%$ efficiency at $0.10 \mathrm{mM}$ concentration, while C6-D shows $\sim 65 \%$ inhibition. Based on these long-term inhibition results, there appears to be no systematic performance of these diphosphonate inhibitors. This may be due to a number of reasons. The long carbon steel specimen exposure (1 week) to the diphosphonate aqueous solution may allow other, competing phenomena to take place, such as Fe oxide dissolution by the additives (particularly for C12-D). This would lead to mass loss and increased corrosion rates. Oxide dissolution by the diphosphonates would generate Fe-inhibitor "complexes" in solution, which may re-precipitate on the steel surface, in an unpredictable manner. Fe-phosphonate adducts are known to have low solubilities [7]. In this case, an added complication is the unknown solubility of the Fe-diphosphonates formed in 
solution, or re-precipitated on the steel surface. Hence, the mass loss results should be received with caution, taking into account the unpredictability of this system, at least in the long-term (1 week duration of the mass loss experiments), which may allow sufficient time for several competing phenomena to take place. Non-systematic variations in corrosion rates (based on mass loss) have been observed in the tetraphosphonate systems reported by us recently [40], but to a lesser extent.

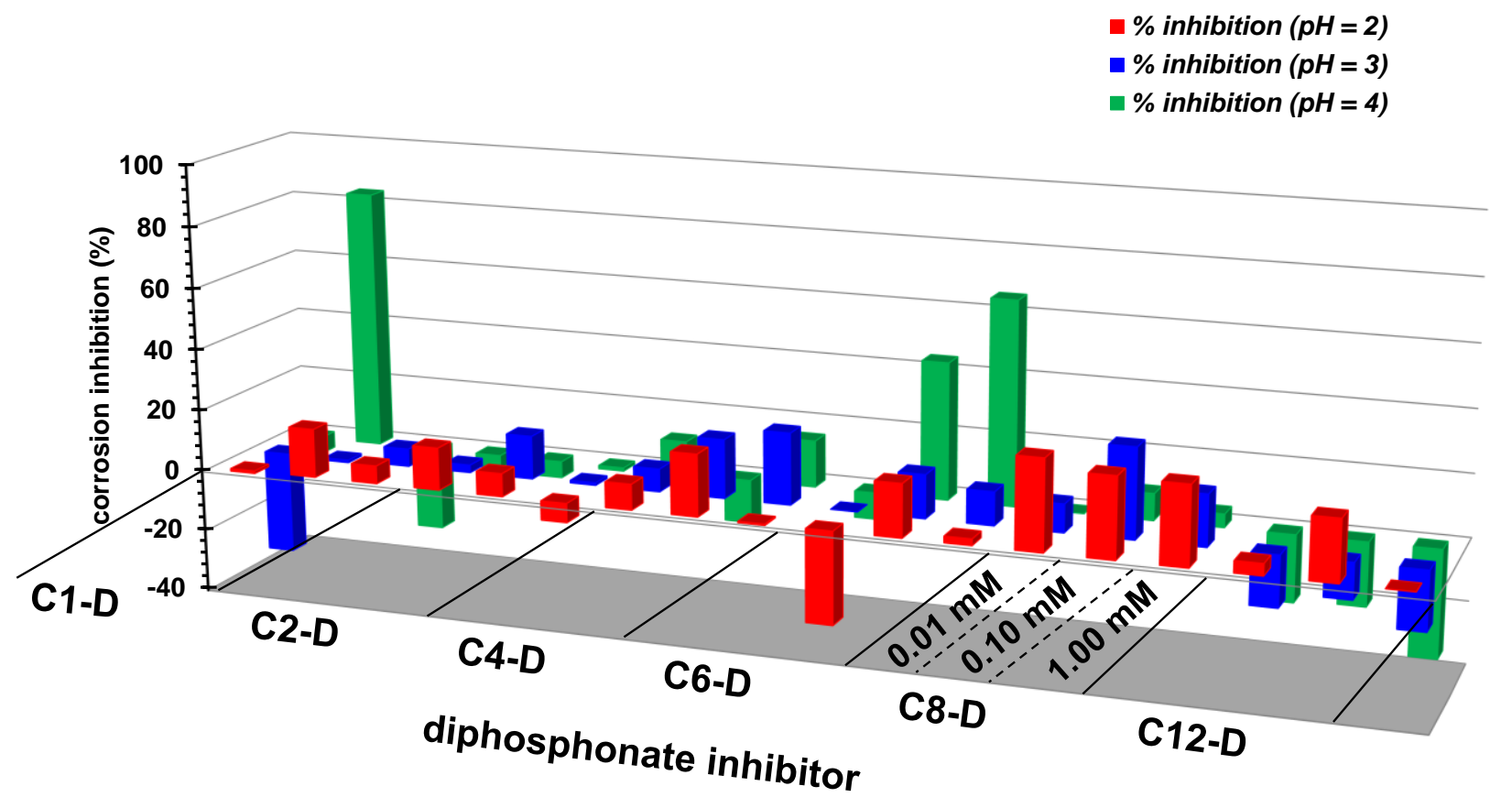

Figure 4. Corrosion inhibition efficiency (\%) in the presence of the diphosphonate additives, at various concentrations $(0.01 \mathrm{mM}, 0.10 \mathrm{mM}$, and $1.00 \mathrm{mM})$ and $\mathrm{pH}$ values $(2.0,3.0$, and 4.0$)$.

\subsection{OCP and potentiodynamic polarization tests}

Further, the behavior of carbon steel in more aggressive environments was studied, because carbon and low-alloy steels are widely used materials in seawater and different brine systems in industrial practice (cooling water systems, desalination plants, injection water). Further electrochemical experiments were carried out in saline media, albeit at higher inhibitor concentration, in order to compensate for the more aggressive medium. The $3.5 \% \mathrm{NaCl}$ solution is used frequently for this purpose. Gravimetric measurements show variable corrosion inhibition efficiencies in acidic solutions with different $\mathrm{pH}$ and concentrations. However, because carbon steel corrosion is more pronounced at low $\mathrm{pH}$ and taking into ac- 
count that $\mathrm{Cl}^{-}$is an aggressive agent, an intermediary $\mathrm{pH}(\mathrm{pH}=3.0)$ was chosen for the studies. Higher inhibitor dosages are frequently required, hence, the concentration of $4.6 \mathrm{mM}$ was chosen for the corrosion inhibition evaluation.

OCP experiments were carried out in freshly prepared solution at ambient temperature. The variation of OCP potential with the immersion time of carbon steel immersed in $3.5 \% \mathrm{NaCl}$ solution in the absence (control) and in the presence of different diphosphonates, at $\mathrm{pH}=3.0$, is illustrated in Figure 5.

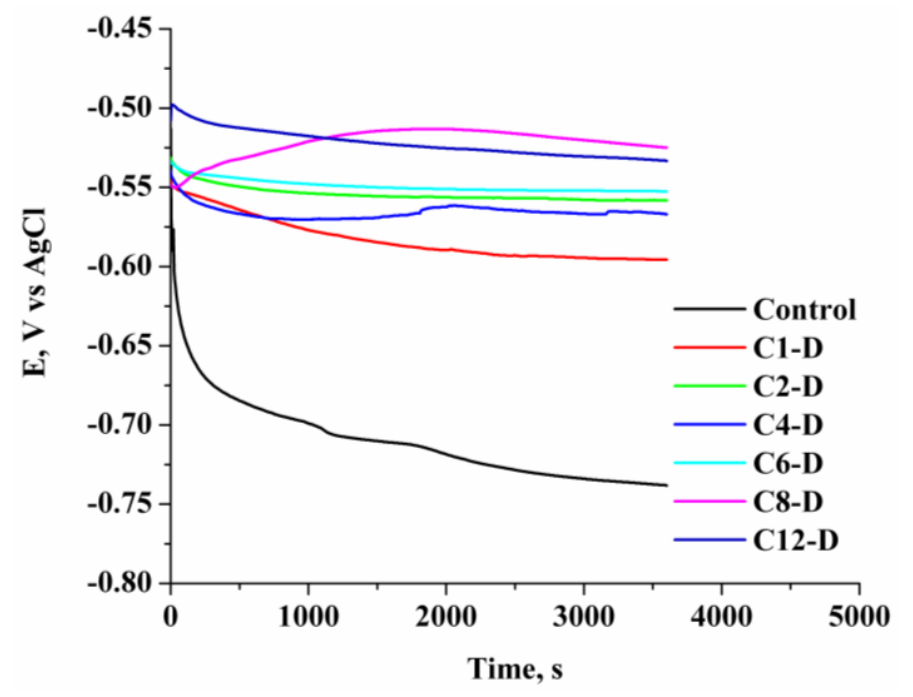

Figure 5. The OCP potential immersion time-dependence for carbon steel in $3.5 \% \mathrm{NaCl}$ solution, at $\mathrm{pH}$ =3.0. without (control) and with various diphosphonates.

The OCP values in the presence of diphosphonic acid inhibitors generally decreased in time due to dissolution of the passive oxide layer present on metal surface by the aggressive chloride ions attack. During the immersion period, limited protection of the surface becomes visible as the corrosion products (formed during immersion) block pores and cracks on the metallic surface. Therefore, a stabilization of the potential was noted. In the case of carbon steel immersed in "control" solution the OCP stabilized after $3000 \mathrm{~s}$. In the presence of inhibitors the OCP stabilized more rapidly, after $600 \mathrm{~s}$. This points to protective layer formation on the metal surface. The OCP values increased in the presence of C4-D, but more evident for C8-D, pointing to the existence of differences in the nature of layers deposited on 
the metallic surface. The potentiodynamic polarization curves recorded for carbon steel in $3.5 \% \mathrm{NaCl}$ solution with and without the diphosphonate additives are shown in Figure 6.

The electrochemical parameters as corrosion potential $\left(\mathrm{E}_{\mathrm{corr}}\right)$, corrosion current density $\left(\mathrm{i}_{\text {corr }}\right)$, polarization resistance $\left(R_{p}\right)$, corrosion rate cathodic $\left(\beta_{c}\right)$ and anodic $\left(\beta_{a}\right)$ Tafel slope were extracted from the polarization curves and are listed in Table S4 in the SI. All parameters represent mean values of three measurements.

The uncertainty of $\mathrm{i}_{\text {corr }}$ lies between 0.26 and $7.9 \%$, for $\mathrm{E}_{\text {corr }}$ between 2.54 and $12.1 \%$ and for CR between 3.16 and $13.3 \%$. The carbon steel specimen immersed in aqueous saline solution with a $\mathrm{pH}$ $\sim 3$ reveals an $\mathrm{E}_{\text {corr }}$ about $-1.052 \mathrm{~V}$ vs. $\mathrm{Ag} / \mathrm{AgCl}$ and a corrosion density current around $8.87 \times 10^{-5} \mathrm{~A} \cdot \mathrm{cm}^{-}$ ${ }^{2}$. A shift of $\mathrm{E}_{\mathrm{corr}}$ to less negative values was observed for all diphosphonate inhibitors. The carbon steel specimen immersed in C-6-D diphosphonate shows an $\mathrm{E}_{\text {corr }}$ about $-0.839 \mathrm{~V}$ vs. $\mathrm{Ag} / \mathrm{AgCl}$ and a corrosion density current of $1.33 \times 10^{-5} \mathrm{~A} \cdot \mathrm{cm}^{-2}$. In C-8-D diphosphonate carbon steel specimen exposes an $\mathrm{E}_{\text {corr }}$ about $-0.632 \mathrm{~V}$ vs. $\mathrm{Ag} / \mathrm{AgCl}$ and a corrosion density current of $5.42 \times 10^{-6} \mathrm{~A} \cdot \mathrm{cm}^{-2}$. E corr values move to more pozitively values in the case of all diphosphonate inhibitors. The protective layer is formed during immersion in inhibitor solutions and the adsorption takes place via the polar phosphonic groups. The phosphonic groups demonstrate high binding affinity for the metallic surface in a mono-, bi- or tridentate manner and create an adherent and compact protective layer. The free elongated alkyl chain functions as a spacer and influences the self-assembly process by interactions between adjacent molecules. It influences the compactness and adherence of the adsorbed layer (film). The highest polarization resistance $\mathrm{R}_{\mathrm{p}}$ value was determined for long alkyl chain diphosphonic acids C8-D and C12-D. 


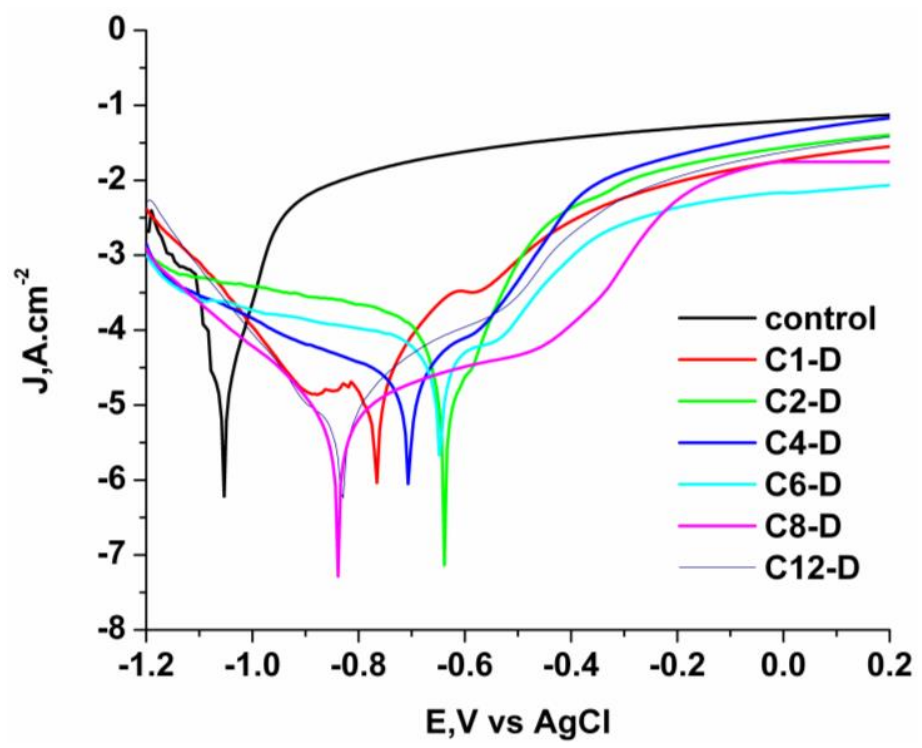

Figure 6. Potentiodynamic polarization curves for carbon steel after 60 min. immersion in $3.5 \% \mathrm{NaCl}$ solutions without (control) and with diphosphonate, at $\mathrm{pH}=3.0$. (scan rate $=1 \mathrm{mV} / \mathrm{s})$.

The $\mathrm{i}_{\text {corr }}$ values for all diphosphonates (Table S4) were lower comparatively with the "control". Long alkyl diphosphonic acids C8-D, C12-D and C6-D present the lowest $\mathrm{i}_{\text {corr }}$ values. The corrosion rate (CR) were lower for the same diphospohantes. In the presence of these diphosphonic acids, the CR was reduced by a factor of 6 . Inhibition efficiency (IE) was calculated according to Equation (1):

$$
I E=\frac{i_{\text {corr }}-i_{\text {inh }}}{i_{\text {corr }}} \times 100
$$

where: IE represents the inhibitory efficiency expressed in $\%, \mathrm{i}_{\text {corr }}$ and $\mathrm{i}_{\text {inh }}$ are the corrosion current density without and with inhibitor, respectively. The best results were achieved in the case of long alkyl chain diphosphonates C8-D (93.89\%), C12-D (89.79\%) and C6-D (85.01\%).

The values of cathodic and anodic Tafel slopes indicate the capability for these inhibitors to adsorb and create an organized layer on the metallic surface. Inhibitors with "long" alkyl chains present higher $\beta_{\mathrm{a}}$ comparatively with "short"-chain inhibitors. The shift to anodic region is due to control of dissolution of iron. Comparing with the anodic Tafel slope value reported in literature for iron in acid media (38 - $40 \mathrm{mV} /$ decade) [49] it can be said that diphosphonic acids work as an anodic and cathodic 
inhibitor. Similar properties were reported for other phosphonic acids [50,51]. The Tafel slopes (except for C6-D) point to the existence of a slow step associated with the adsorption of inhibitor, in the mechanism of iron dissolution. For anodic polarization branch, it can be seen from Figure 10 that, in the presence of diphosphonic acids, the anodic current decrease in the low polarization potential region with a different slope and increases rapidly after passing a certain potential in the high polarization region. This behavior was previously reported in literature for iron in acid solutions $[52,53,54]$.

The inhibition mode depends on electrode potential. The increase in anodic current in the high polarization potential region is linked to the quality of the layer and to the adsorption / desorption of inhibitor molecules on the electrode. The drop of anodic current in the low polarization potential region indicates also an increase in the resistance of diffusion process at the electrode. This denotes the fact that at the more anodic potential the layer formed on metallic surface becomes thicker or less porous (more compact). Other phosphonic acids, such as the polymeric polyethyleneiminemethylene phosphonic acid (PEIMPA), demonstrate the same effects [53]. The corrosion inhibition in acid solution can be rationalized by considering that the PEIMPA molecules are easily protonated and the polycation adsorption is mainly responsible for the protective properties of this compound $[40,53,55,56]$.

The films formed on metal surface in the presence of diphosphonic acids were analyzed by ATR-FTIR. The recorded spectra of films formed on the metallic surface are shown in Figure 7 and reveal the presence of strong asymmetric phosphonate $\left(-\mathrm{PO}_{3}{ }^{2-}\right)$ stretch band at $1032 \mathrm{~cm}^{-1}$ in organophosphonate layers formed and confirm the presence of inhibitor on carbon steel surface. Also, the bands attributed to $\mathrm{P}=\mathrm{O}$ and $\mathrm{P}-\mathrm{O}-\mathrm{C}$ bonds appear at $1361 \mathrm{~cm}^{-1}$ and $1026 \mathrm{~cm}^{-1}$ respectively. . At $2845 \mathrm{~cm}^{-1}$ and $2928 \mathrm{~cm}^{-1}$ the scissor deformation and asymmetric deformation bands associated with the methylene group are present. The bands at $1375 \mathrm{~cm}^{-1}$ and $3412 \mathrm{~cm}^{-1}$ were attributed to $\mathrm{N}-\mathrm{H}$ bonds and the broad band at $\sim 3300 \mathrm{~cm}^{-1}$ was attributed to $\mathrm{OH}$ stretching vibrations. The absorption peak of $\mathrm{OH}$ stretching vibrations $\left(3300 \mathrm{~cm}^{-1}\right)$ overlaps with the band for $\mathrm{N}-\mathrm{H}$. These bands are reduced for C1-D, C4-D, C8-D and C12-D due to intermolecular hydrogen bonds between the adsorbed phosphonate molecules and iron surface. [57,58]. 


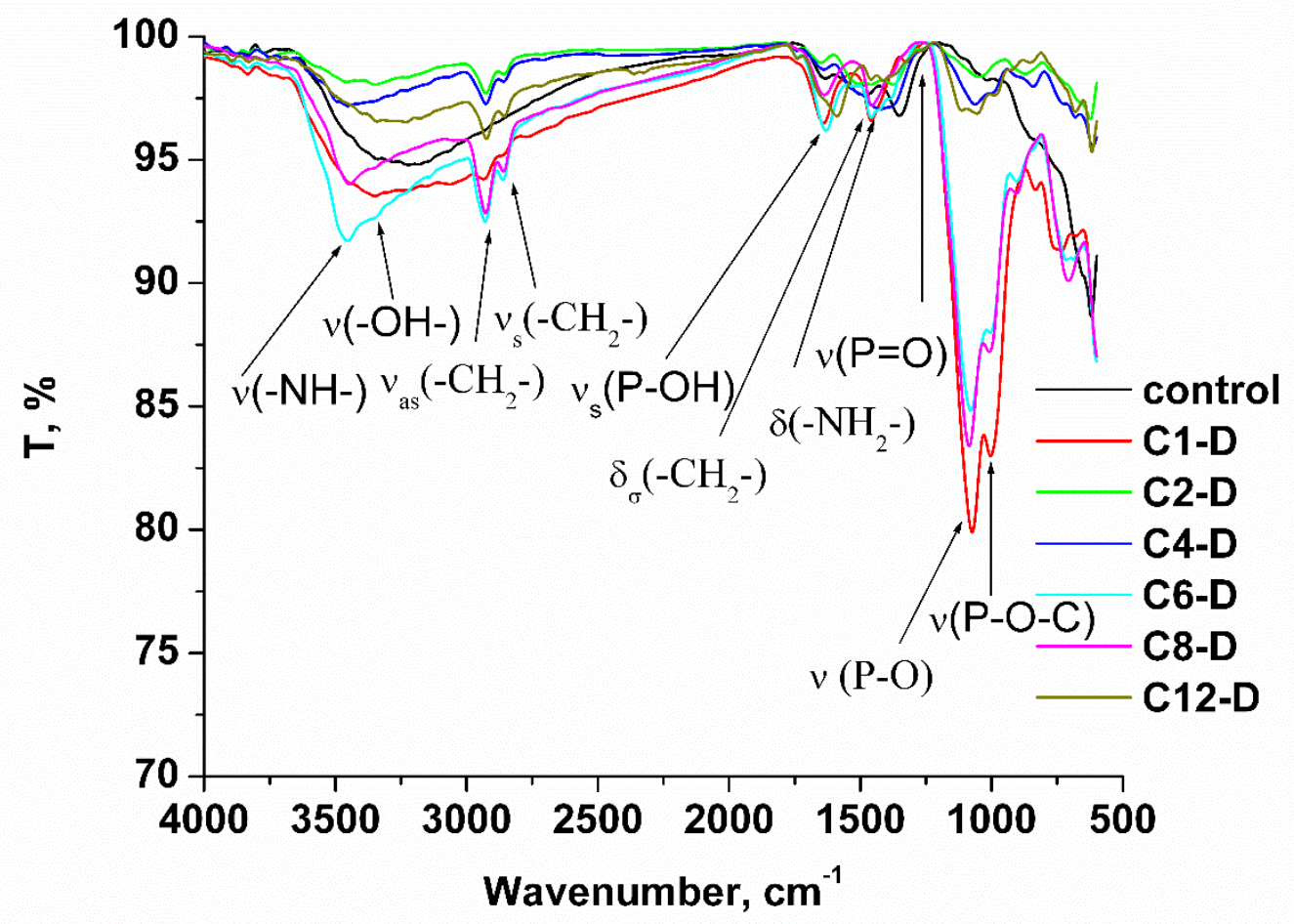

Figure 7. ATR-FTIR spectra for specimens immersed for 1 hour in $3.5 \% \mathrm{NaCl}$ solutions in the presence of diphosphonic acid inhibitors, at $\mathrm{pH}=3.0$.

The absorption peaks at 1330 and $1150 \mathrm{~cm}^{-1}$ appear only in the presence of diphosphonic acids (not observed for control solution) and are linked to the bonds $\mathrm{P}=\mathrm{O}$ and $-\mathrm{P}-\mathrm{OH}$. The intensity absorption peaks at $1330 \mathrm{~cm}^{-1}$ may be correlated with the binding mode via the $\mathrm{P}=\mathrm{O}$ bond. The absence of these absorption peaks $\mathrm{P}=\mathrm{O}$ and $\mathrm{P}-\mathrm{O}^{-}$indicates a tridentate, rather than bi-dentate, or mono-dentate, bonded phosphorus [58,59]. The absence of absorption peaks at $1330 \mathrm{~cm}^{-1}$ in the case of C8-D suggests a tridentate binding for this inhibitor and generation of a compact layer. The methylene absorption bands presented in ATR-IR spectra also confirm surface coverage by the inhibitors. The intensity of asymmetrical stretching vibrations of methylene groups appeared at $2926 \mathrm{~cm}^{-1}$, symmetric stretching vibrations appeared at $2857 \mathrm{~cm}^{-1}$ and the scissoring mode of methylene appeared at $1463 \mathrm{~cm}^{-1}$. The asymmetric methylene stretching vibrations appear at higher wave number than the value reported in the literature for a well ordered alkyl phosphate thin films $\left(2922 \mathrm{~cm}^{-1}\right)$. This difference indicates the presence of some 
conformational disorder. To evaluate the conformational disorder in the adsorbed layer the intensity ratio $I_{2857} / I_{2926}$ was calculated [60]. The high value of this ratio indicates the formation of a more ordered layer. The C8-D, C6-D and C12-D present almost the same value (0.78) and reveal the same degree of conformational order. A low value for this ratio $(\sim 0.62-0.70)$ was observed in the case of inhibitors C1-D, C4-D and C2-D and suggests a highly disordered layer formed on the metallic surfaces. The results reveal that inhibitors with small alkyl chain were adsorbed in a less organized mode on the carbon steel surface than inhibitors with long alkyl chain. The analysis obtained based on the ATR-IR measurements agrees with $\mathrm{CP}$ and EIS measurements, suggesting that the metal surface was protected with diphosphonic acids by an adsorption process.

\subsection{Electrochemical Impedance Spectroscopy (EIS) Measurements}

In the Nyquist graph (Figures 8a and b), the imaginary component of the impedance is plotted as a function of the real component reveals flattened semicircles with a higher diameter of the semicircle in the presence of diphosphonic acids. The Bode representations show the logarithm of the impedance modulus $\mid \mathrm{ZI}$ and phase angle as a function of the logarithm of the frequency f (Figure 8c and Figure 8d, respectively).

The Bode modulus plot is in agreement with that of semicircle diameter in Nyquist plots and show different behavior associated with the structure of diphosphonic acid (the length of alkyl chain). In Bode phase (Figure 8c) one time constant at low (LF) to middle frequency and an incomplete time constant at high frequencies (HF) were observed, their position depending on inhibitor used. The semicircles at the lower frequency and middle to higher frequency are due to electrochemical corrosion processes. The capacitive loop detected at HF is linked to the layer properties and to non-homogenous current distribution on the electrode surface. The changes in the phase maximum with inhibitor indicate the differences in the relaxation time constants. For electrodes immersed in solution with inhibitors the corrosion reaction takes place in the region where the layer is absent (uncovered regions) or in pores as is 
illustrated in Figure S25. The electrical equivalent circuit used to model the experimental data contains the solution resistance $R_{s}$, pore resistance $R_{\text {pore }}$ and charge transfer resistance $R_{c t}$. The capacitance $C_{d l}$ represents the double layer capacitance and CPEa represent the intact adsorbed inhibitor layer capacitance. The equivalent circuit contains an additional Warburg diffusion element at the metallic/layer interface to describe mass transport control, define by Eq. 2:

$Z_{W}=\sigma \cdot \omega^{-1 / 2}(1-j)$

where: $\sigma$ represents the Warburg coefficient (in $\mathrm{ohm} \cdot \mathrm{cm}^{2} \cdot \mathrm{s}^{-1 / 2}$ ), $\omega$ is the angular frequency (in $\mathrm{rad} \cdot \mathrm{s}^{-1}$, with $\omega=2 \pi \mathrm{f}$, where $\mathrm{f}$ is the frequency in $\mathrm{Hz}$ ), and $j$ is the imaginary unit.

Constant phase element (CPE) was used in the simulation, instead of the perfect double-layer capacitor due to the electrode roughness. The CPE element is defined by the parameters CPE-T (T) and CPE-P $(\varphi)($ Eq. 3a) and the parameter T is proportional to the capacitance of the double-layer (Eq. 3). A CPE-P parameter equal to 1 will give a perfect capacitor (Eq. 3b).

$$
\begin{aligned}
& Z_{C P E}=\frac{1}{T(J . \omega)^{\phi}} \\
& T=C_{d s}^{\varphi}\left(R_{s}^{-1}+A\right)^{1-\varphi}
\end{aligned}
$$

where $0<\varphi<1$ describes the deformation of the circle in the complex plane and Q is a constant. If $\varphi=$ $1 \mathrm{CPE}$ becomes a perfect capacitor. In the above:

$\mathrm{C}_{d s}^{\phi}=$ capacity of the double-layer, in $\mathrm{F}$

$\mathrm{R}_{\mathrm{s}}=$ solution resistance, in $\Omega$

$\mathrm{A}=$ electrode surface area, in $\mathrm{cm}^{2}$ 
$\mathrm{J}=$ current density in $\mathrm{A} \cdot \mathrm{cm}^{-2}$

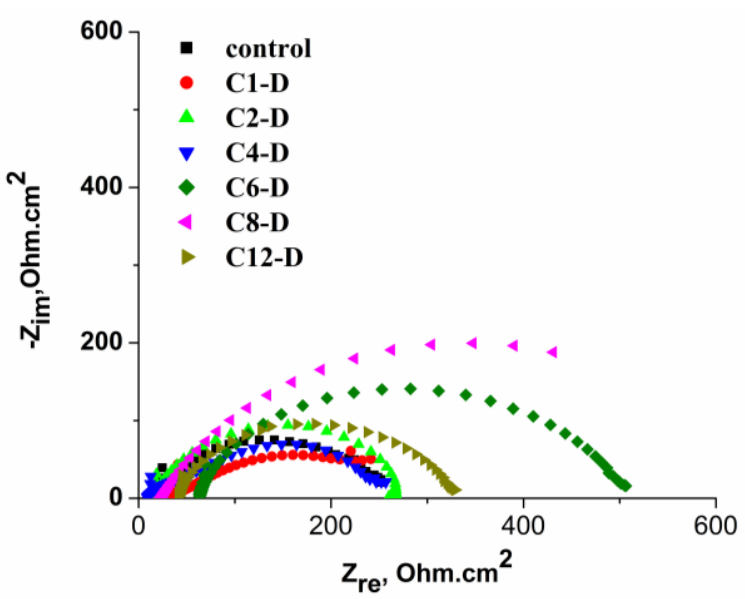

(a)

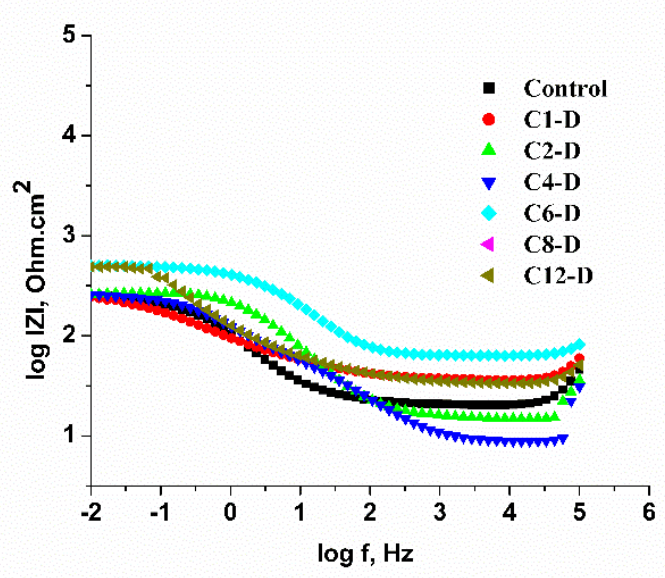

(c)

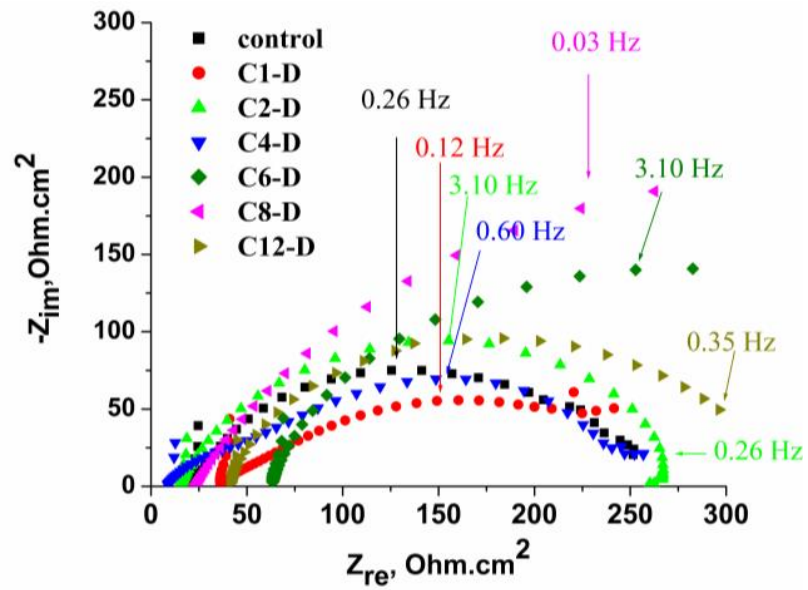

(b)

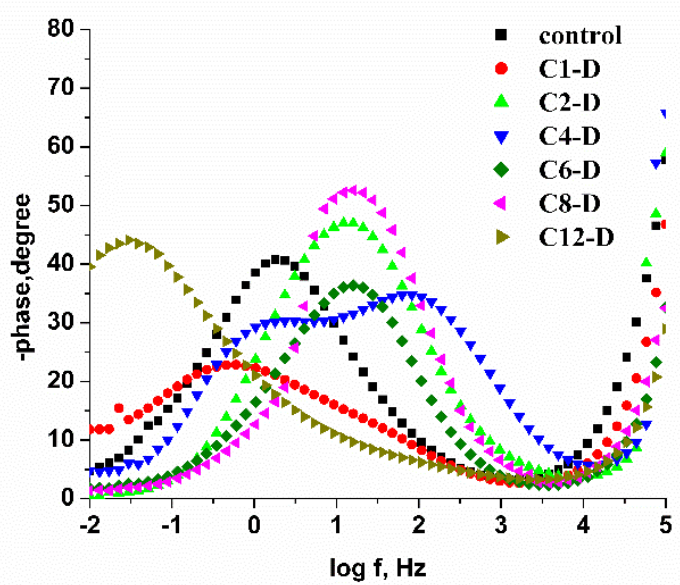

(d)

Figure 8. Complex plane Nyquist plots (a), complex plane Nyquist plots detail (b) and Bode plots logarithm of the impedance modulus $|\mathrm{Z}|$ (c) and phase angle as a function of the logarithm of the frequency $\mathrm{f}$ (d) for carbon steel immersed for 1 hour in $3.5 \% \mathrm{NaCl}$ solutions in the presence of diphosphonic acids, at $\mathrm{pH}=3.0$.

The EEC model (Figure 9a) reveals the correlation between simulated and experimental data (Figure 9b). The lower reproducibility observed in the HF is most likely due to the electrode roughness. The obtained results are presented in Table S5 in the SI. Uncertainties of $\mathrm{R}_{\mathrm{Ct}}$ parameters are in the range 

and for $\mathrm{CPE}_{\mathrm{dl}}-\mathrm{T}$ between 1.56 and $11.3 \%$.

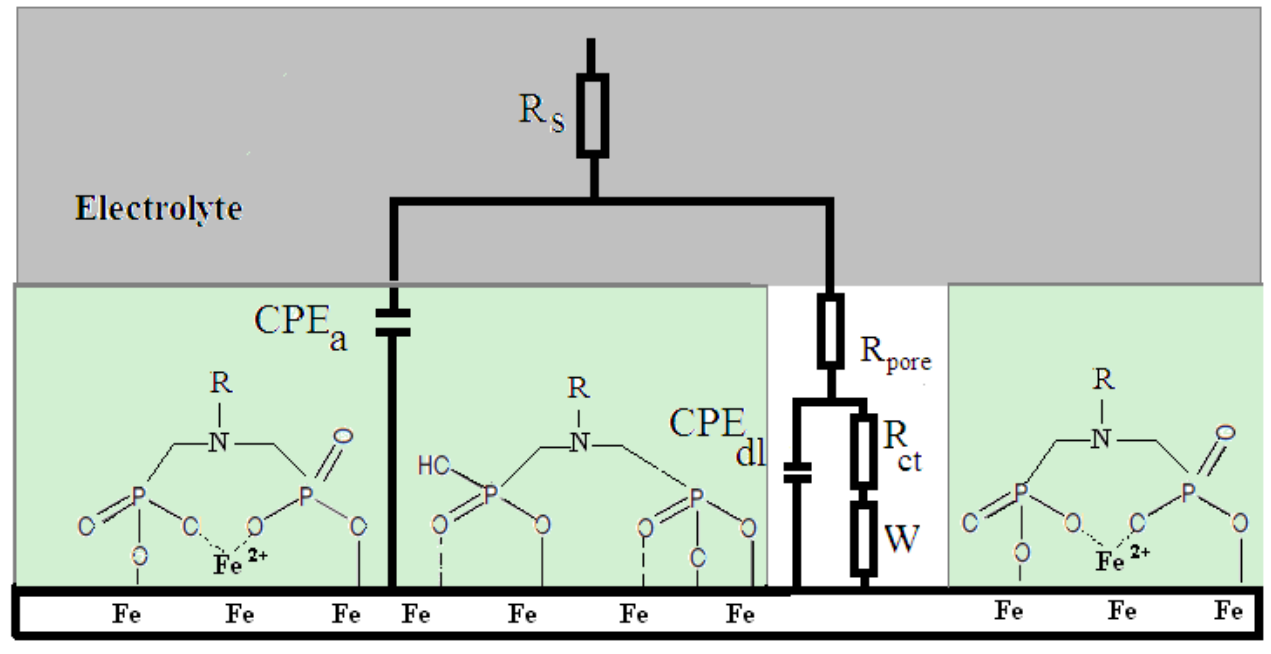

(a)
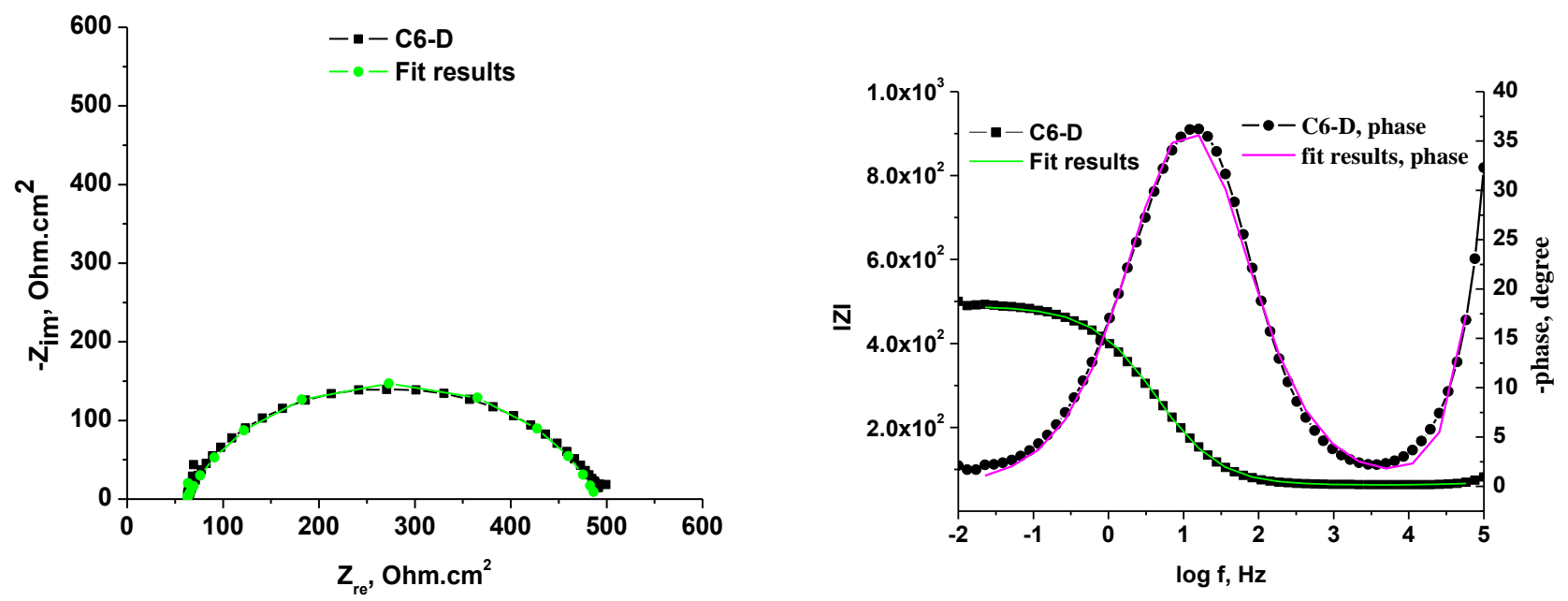

(b)

Figure 9. (a) Schematic representation of the adsorbed layer on carbon steel in the presence of inhibitor and equivalent electric circuit (EEC) proposed for modeling the EIS data for carbon steel immersed in $3.5 \% \mathrm{NaCl}$ solutions in the presence of diphosphonic acids. (b) Representative example of a simulation of Nyquist and Bode diagrams with suggested model for the C6-D inhibitor.

The variation in solution resistance $\mathrm{R}_{\mathrm{s}}$ appears due to the corrections made because of $\mathrm{pH}$ adjustments to $\sim 3$. Diphosphonates with longer alkyl chains exhibit lower solubility and require $\mathrm{NaOH}$ addition, and subsequent readjustment of the $\mathrm{pH}$ with $\mathrm{HCl}$. The EIS data reveal that C4-D, C6-D and 
C8-D layers exhibit CPE exponents above 0.9, indicating a high-quality, robust layer. The capacitance value depends on the protective layer thickness or the dielectric constant. The approximate thickness of each layer may be estimated from Eq. (4):

$$
C=\frac{\varepsilon_{r} \varepsilon_{0} A}{d}
$$

where: $\mathrm{C}$ represents the capacitance, $\varepsilon_{\mathrm{o}}$ the void permittivity, $8.8 \times 10^{-12} \mathrm{~F} \cdot \mathrm{m}^{-1}, \varepsilon_{\mathrm{r}}$ the dielectric constant of the protective layer, A the area in $\mathrm{cm}^{2}$ and $\mathrm{d}$ the thickness of the coating (layer). The capacitance value could decrease due to an increase of protective layer thickness or to decrease in dielectric constant of protective layer.

The changes in the adsorbed layer capacitances $\mathrm{CPE}_{\mathrm{a}}$ provide indications about the formed layer. Assuming that both dielectric constant of the layers and area of the electrode surface are similar, the changes appear due to the differences in the layer thickness. Considering a value equal to 6.29 for the dielectric constant of the inhibitor layer (value reported for phosphonic compounds [61]) thicker layers were obtained for C8-D $(390 \mu \mathrm{m})$, C6-D (828 nm) and C12-D (356 nm). The inhibitors C2-D (86 nm), C1-D (205 nm) and C4-D (153 nm) form thinner layers. The values are in accordance with IE \% from the CP data (Table S5 in the SI). The results reveal formation of a thinner layer on electrode surface for the short-chain diphosphonates, and, as a consequence, a lower coverage of the surface or even the inability to cover effectively the entire metallic surface. It seems that the long-chain diphosphonates (C6-D, C8-D and C12-D) tend to show more effective adherence to the metallic surface, inducing higher coverage and thicker protective layers.

This $\mathrm{R}_{\text {pore }}$ resistance represents the sum of the resistance of individual pores filled with electrolyte. The path through the pores in the adsorbed layer allows the contact of the electrolyte with the metallic surface. For the C6-D, C8-D and C12-D the layer resistances are much higher indicating the buildup of a compact and/or less porous layer on the metallic surface. 
The charge-transfer resistance $\left(R_{c t}\right)$ values increase with the alkyl chain length as the formed layer becomes more compact and thicker. The $\mathrm{R}_{\mathrm{ct}}$ values for C8-D, C6-D and C12-D obtained from fitting the EIS data with the equivalent circuit model (Figure 9a) were estimated to be 528, 352 and 225 $\Omega \cdot \mathrm{cm}^{2}$, respectively, while that of the untreated carbon steel was $19.3 \Omega \cdot \mathrm{cm}^{2}$. The robustness of the deposited layer is determined by the capacity of each inhibitor to bind to the metal and to generate a firm coating. Lower values indicate the presence of pores or defects. Diphosphonate inhibitors with a number of methylene groups $\geq 6$ present higher $R_{c t}$ values. The high $R_{c t}$ values were obtained in the case of C8-D, C6-D and C12-D, were surface coverage is also high. The highest value was obtained for C8-D. This is corroborated by the ATR-IR data, which reveal a tridentate phosphonate binding mode. C8-D forms a thicker layer on the metal surface. $\mathrm{C}_{\mathrm{dl}}$ and $\mathrm{R}_{\mathrm{ct}}$ are influenced by inhibitor adsorption onto the metal surface and its capacity to cover the surface $(\theta)$. Higher $R_{c t}$ and lower $C_{d l}$ values are obtained in the case of inhibitors capable to strongly bind onto the carbon steel surface (C6-D, C8-D and C12-D), forming P-O-Fe type bonds. Inhibitors with longer alkyl chains (length of 6 to 12 methylene units) are able to bind to the carbon steel surface in a manner that provides an adherent and compact layer. The $\mathrm{CPE}_{\mathrm{dl}}-\mathrm{P}$ exponents are lower than unity (range between $0.70-0.81$ ) and prove the non-homogeneity of the metal surface. Based on EIS data, inhibition efficiency IE (\%) and surface coverage $\theta$, were calculated (Eqs. 5a and 5b, respectively):

$$
\begin{aligned}
& I E=\frac{R_{c t}^{i n h}-R_{c t}^{\text {control }}}{R_{c t}^{i n h}} \cdot 100 \\
& \Theta=\frac{I E}{100}
\end{aligned}
$$

where: $R_{c t}{ }^{i n h}$ is the charge transfer resistance for electrode in the presence of inhibitor, $R_{c t}{ }^{\text {control }}$ is the charge transfer resistance for electrode in solution without inhibitor.

The IE, determined from EIS data, reveals highest results for C8-D (96.35\%), C12-D (91.43\%), C6-D (94.52\%), followed by C2-D (63.86\%), C4-D (56.11\%) and C1-D (51.52\%). The experiments 
EIS and CP are conducted on the same sample. During EIS some changes in the protective layer formed in the presence of inhibitors C1-D, C4-D C2-D on carbon steel surface, occurred. The Fe-inhibitor complexes formed in solution, which present low solubility, may re-precipitate on the steel surface and block the existing pores on the iron surface [7]. As a result, a higher IE value for these inhibitors was determinate from the EIS data. Although there are differences between the values offered by the two measurements for the same inhibitor, each method indicates the same efficacy behavior for the diphosphonic acids series. This inhibition efficiency is comparable with the values reported for alkyl phosphate layers $[40,62]$.

The porous inhibitor layer constrains the corrosion by the diffusion of ions through the layer, and mass transport limitation would lead to an additional resistance. A Warburg-like behavior at low frequencies was attributed to an inhomogeneous current distribution caused by the complicated mass transport processes within the pores. The value of Warburg impedance coefficient, $\sigma$, represents the resistance originating from the diffusion process through the pores within the corrosion layer. An increase in the Warburg impedance coefficient indicates an increase in the resistance of the diffusion process at the electrode and implies that the layer becomes thicker or less porous.

The metallic surface affinity for the phosphonic groups plays an important role in the construction of protective layer and the inhibitor structure can be responsible for the compactness and adherence of the layer. The adsorption process is usually described through adsorption isotherms. The values of surface coverage $\theta$ (equation $5 \mathrm{~b}$ ) were determined from EIS data and used to get the correct isotherms by the Eq. 6 [63].

$$
\frac{C}{\theta}=\frac{1}{K_{a d s}}+C
$$

where: $\theta$ is the surface coverage, $\mathrm{C}$ is the inhibitor concentration, $K_{\mathrm{ads}}$ is the adsorption equilibrium constant. 
Figure 10 illustrates the linear plots for $(\mathrm{C} / \theta)$ in function of $\mathrm{C}$. The adsorption of diphosphonic acids on carbon steel follows the Langmuir isotherm (correlation coefficient nearby to unity).

The diphosphonates present the same tendency to be adsorbed on the metal surface as other phosphonic acids and obey the Langmuir adsorption isotherm $[17,64,65]$. The $K_{\text {ads }}$ values give information about the strength of the interaction between the inhibitor and the metal surface. A higher value implies more efficient adsorption.

$$
R_{L}=\frac{1}{1+K_{a d s} C}
$$

The highest $K_{\text {ads }}$ value was obtained for C8-D followed by C12-D and then C6-D. The important aspect of the Langmuir isotherm can be expressed in terms of a $\mathrm{R}_{\mathrm{L}}$ separation (dimensionless constant), described by Eq. 7. A lower value indicates a highly favorable adsorption process [66]. It was observed that the value of $\mathrm{R}_{\mathrm{L}}$ is less than unity, confirming the favorable uptake of the inhibitor. Lower $\mathrm{R}_{\mathrm{L}}$ values at higher inhibitor concentrations showed that adsorption was more favorable at higher concentrations. Comparison of the diphosphonate inhibitor molecules based on the dimensionless separation factor, $\mathrm{R}_{\mathrm{L}}$, leads to the conclusion that short-chain diphosphonates demonstrate a less favorable adsorption process and that the formation rate of the protective layer on the metal interface is slower than that in the case of long-chain diphosphonates and tetraphosphonates [40]. It is seems that for C1-D, C2-D and C4-D the short carbon chain is disadvantageous in removing water molecules from the solid-water interface. In equivalent conditions short-chain molecules require a long time to approach and "dock" onto the surface in order to provide a well-organized layer. The longer chain molecules are predisposed to accumulate and pack at the metallic surface more easily. Similar behavior was reported for carbon steel surfaces immersed in mono-n-butyl phosphate and mono-n-hexyl phosphate aqueous solutions [62]. The surface tension results indicated that longer alkyl chain molecules showed a stronger tendency to diffuse from 
the bulk solution (bulk electrolyte phase) and accumulate at the air-electrolyte interface, than small alkyl chain molecules [62].

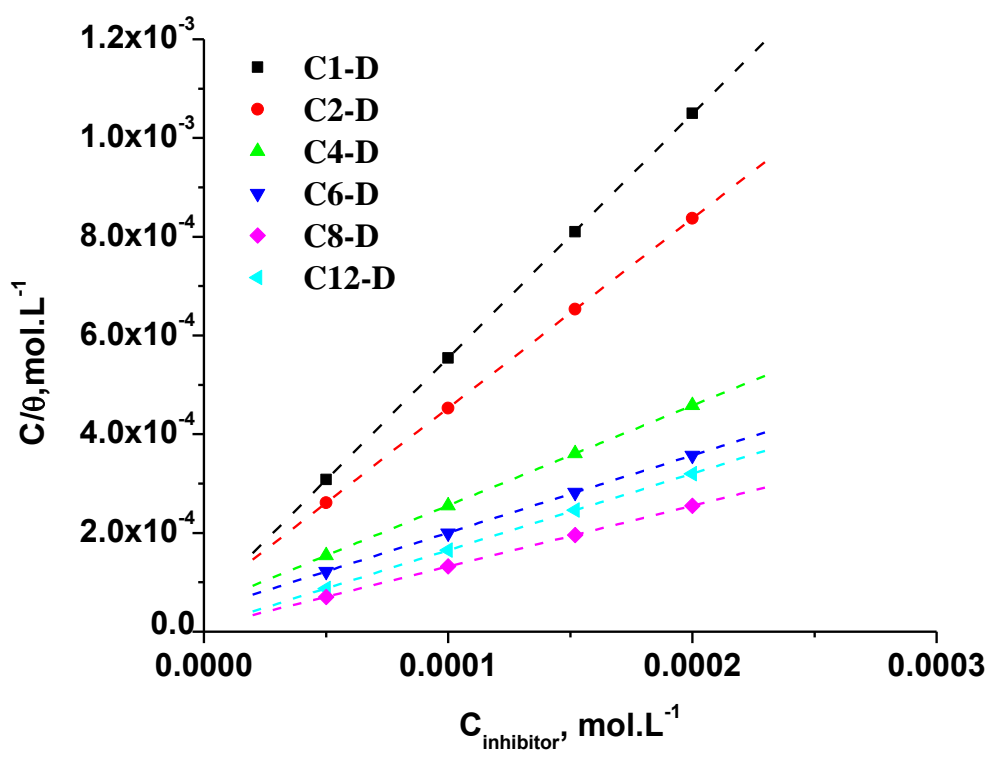

Figure 10. The isotherm Langmuir plots for the tested diphosphonate inhibitors.

Table 2. Values of the $\mathrm{K}_{\mathrm{ads}}, \Delta \mathrm{G}_{\text {ads }}^{\circ}$ and $\mathrm{R}_{\mathrm{L}}$ for adsoption of diphosphonic acids molecules on carbon steel surface.

\begin{tabular}{lcccccc}
\hline Inhibitor & C1-D & C2-D & C4-D & C6-D & C8-D & C12-D \\
\hline $\mathbf{K}_{\text {ads, }}, \mathbf{m o l}^{-1}$ & 16658.34 & 14513.79 & 19047.62 & 23041.47 & 111234.71 & 100110.12 \\
$\Delta \mathbf{G}_{\text {adss }}^{\circ}, \mathbf{K J} / \mathbf{m o l e}$ & -34.04 & -33.69 & -34.36 & -34.83 & -38.73 & -38.48 \\
$\mathbf{R}_{\mathbf{L}}$ & 0.38 & 0.41 & 0.34 & 0.30 & 0.08 & 0.09 \\
\hline
\end{tabular}

Generally, $\Delta G^{\circ}{ }_{a d s}$ values indicative of physisorption appear around $-20 \mathrm{~kJ} \cdot \mathrm{mol}^{-1}$ or more positive, whereas values around $-40 \mathrm{~kJ} \cdot \mathrm{mol}^{-1}$ or more negative favor chemisorption [67]. The negative $\Delta \mathrm{G}_{\text {ads }}^{\circ}$ and high $\mathrm{K}_{\mathrm{ads}}$ values obtained for the diphosphonates (Table 2) show a spontaneous adsorption and, according to adsorption data, covalent/electrostatic interactions exist. The values are generally higher compared to those for the tetraphosphonate inhibitors [40,62]. The electrostatic interactions and hydrogen bonds between oxygen atoms from phosphonate groups and $\mathrm{Fe}-\mathrm{OH}$ groups are further respon- 
sible for surface immobilization, as confirmed by the XPS and ATR-FTIR spectra. The $\Delta \mathrm{G}_{\text {ads }}^{\circ}$ values (33-38 $\mathrm{kJ} \cdot \mathrm{mol}^{-1}$ ) imply the physisorption and chemisorption tendency of the diphosphonates. The length of the alkyl chain is an important aspect in layer formation. Inhibitors with shorter alkyl chains, such as C1-D, C2-D and C4-D, possess lower $\mathrm{K}_{\mathrm{ads}}$ values and a significant tendency for physisorption and low degree of steel surface coverage, compared to the inhibitors with longer alkyl chains.

The alkyl chain length affects both the degree of coverage and packing of the film formed on the metal surface. A short length cannot achieve sufficient surface coverage in the case of both di- and tetraphosphonates. For phosphonates with more than four or six methylene units in their backbone, the surface the degree of coverage increases. The compactness of the film depends on the time required for the molecule to reach the metal surface from the bulk electrolyte and to be adsorbed and pack on it. Longer "escape" times from the bulk electrolyte phase means a delay in protective film formation and coverage of the metal surface. Short alkyl chain molecules require longer time to approach and "dock" onto the metallic surface compared to medium and long alkyl chain ones, the latter tending to accumulate more rapidly at the metal-electrolyte interface. The diphosphonates show the lowest corrosion rates and good packing for molecules with long alkyl chain (C8-D and C12-D). For tetraphosphonates this is true for molecules with medium length alkyl chain (C4 and C6) [40].

The diphosphonates (at a $4.6 \mathrm{mM}$ concentration in saline solution at $\mathrm{pH}=3$ ) yield corrosion inhibition efficiencies ranging from $80 \%$ to $94 \%$, higher than for tetraphosphonates [40]. The elongated chains (alkyl chain) act as a spacer and influence the self-assembly process and the interaction between nearby molecules and therefore the density of the protective layer formed on metal surface.

Diphosphonates with long alkyl chains present the best results regarding inhibition efficiency (determined from EIS data): C8-D (96.35\%), C12-D (91.43\%) and C6-D (94.52\%). A comparison between long alkyl chains diphosphonates show that the metallic iron detected by XPS is lowest in the case of C8-D. This is likely to be due to the longer chain-length of C8-D compared to the C6-D and the smaller molecules. It also implies that the C8-D molecule packs more closely than C12-D on the surface so that less of the Fe substrate is measured. In addition, the ratio between the oxide species point to a 
different kind of ordered structure and may be an explanation for the different chemical and diffusional behavior of the protective layers. The absorbed diphosphonate inhibitors form a film on the metallic surface that acts as a physical barrier, and restricts the diffusion to or from the metal surface of corrosive species. The first stage of iron oxidation implies the formation of $\mathrm{FeO}$, an oxide that is stable only in the absence of oxygen. Subsequently, in the presence of oxygen, the iron oxide is converted into iron hydroxide $\left(\mathrm{Fe}_{2} \mathrm{O}_{3} \cdot \mathrm{H}_{2} \mathrm{O}\right)$ or $\mathrm{FeO}(\mathrm{OH})$. The high quantity of $\mathrm{FeO}$ detected in the $\mathrm{C} 8$-D layer (Table 2) implies that $\mathrm{FeO}$ oxidation is suppressed and the layer is more passive. C6-D and C12-D also suppress further oxidation of $\mathrm{FeO}$, but the detected quantity of $\mathrm{Fe}(0)$ in the generated layer is higher and, consequently, the deposited layer is less thick and less compact, either due to bonding via only one phosphonate group, steric reasons, or possibly the presence of unbound diphosphonate at the surface.

The use of organic phosphonic acids to protect carbon steel are reported in literature as they present low toxicity, high stability and corrosion inhibition properties. Table 3 summarizes the corrosion currents, inhibition efficiencies and adsorption isotherm of different compounds (majority phosphonates) as corrosion inhibitors for the iron and our results.

Table 3. The corrosion currents, inhibition efficiencies and adsorption isotherm of different compounds and phosphonates on the iron in various solutions

\begin{tabular}{|c|c|c|c|c|c|}
\hline Inhibitor / concentration & Medium & $\begin{array}{c}\mathrm{J}_{\text {corr }} \\
\mu \mathrm{A} / \mathrm{cm}^{2}\end{array}$ & IE, \% & $\begin{array}{c}\text { Adsoption } \\
\text { isotherm }\end{array}$ & Reference \\
\hline $\begin{array}{l}\text { Hydroxyethyl (HEI-12) / } 25 \\
\text { ppm }\end{array}$ & $3 \% \mathrm{NaCl}$ & 150 & 21 & & 3 \\
\hline $\begin{array}{l}\text { Hydroxyethyl modified with } \\
\text { oleic chain from coconut oil } \\
\text { (HEI-M) / 10ppm }\end{array}$ & $3 \% \mathrm{NaCl}$ & 160 & 26 & & 3 \\
\hline $\mathrm{MoO}_{4}{ }^{2-} / 100 \mathrm{ppm}$ & $0.1 \mathrm{M} \mathrm{HCl}$ & - & 82 & Langmuir & 4 \\
\hline $\mathrm{WO}_{4}^{2-} / 100 \mathrm{ppm}$ & $0.1 \mathrm{M} \mathrm{HCl}$ & - & 65 & Langmuir & 4 \\
\hline $\begin{array}{l}\text { O,O'-dialkyldithiophosphate } \\
\text { (SOD2) / } 60 \text { ppm }\end{array}$ & $1 \mathrm{M} \mathrm{HCl}$ & 26.09 & 98.74 & Langmuir & 5 \\
\hline $\begin{array}{l}\text { Hexamethylenediamine- } \\
\text { tetrakis(methylenephosphonic } \\
\text { acid) (HMDTMP) / } 4 \mathrm{mM}\end{array}$ & $0.5 \mathrm{M} \mathrm{HCl}$ & 25 & 93 & Langmuir & 17 \\
\hline $\begin{array}{l}\text { Diethylenetriaminepentamethyle } \\
\text { nephosphonic acid }\end{array}$ & Sea water & 5.238 & 70 & - & 19 \\
\hline
\end{tabular}




\begin{tabular}{|c|c|c|c|c|c|}
\hline \multicolumn{6}{|l|}{$\begin{array}{l}\text { (DTPMP)/DTPMP }(250 \mathrm{ppm})+ \\
\mathrm{Ni}^{2+}(50 \mathrm{ppm})\end{array}$} \\
\hline $\begin{array}{l}\text { Amino- } \\
\text { tris(methylenephosphonic acid) } \\
\text { (ATMP) / } 5 \mathrm{mM}\end{array}$ & $1 \mathrm{M} \mathrm{HCl}$ & 175.4 & 77.41 & Langmuir & 20 \\
\hline $50 \mathrm{mM}$ & & 109.3 & 94.52 & & \\
\hline $\begin{array}{l}\text { 2-mercaptobenzimidazole } \\
(\mathrm{MBI}) / 2 \mathrm{mM}\end{array}$ & $1 \mathrm{M} \mathrm{HCl}$ & 8 & 98 & - & 33 \\
\hline $\begin{array}{l}\text { Hexamethylenediamine- } \\
\text { tetrakis(methylenephosphonic } \\
\text { acid) (HMDTMP) / } 4.9 \mathrm{mM}\end{array}$ & $\begin{array}{c}3.5 \% \mathrm{NaCl}, \mathrm{pH} \\
=3\end{array}$ & 4.03 & 87.99 & Langmuir & 40 \\
\hline $\begin{array}{l}\text { Piperidin-1-yl-phosphonic acid } \\
\text { (PPA) / } 4 \text { mM }\end{array}$ & $1 \mathrm{M} \mathrm{H}_{2} \mathrm{SO}_{4}$ & & 91.38 & Langmuir & 50 \\
\hline $\begin{array}{l}\text { 1-hyroxyethane-1,1- } \\
\text { diphosphonicacid }(\mathrm{HEDP})+ \\
\text { sodium tungstate }(\mathrm{ST})+\mathrm{Zn}^{2+} \\
200 \mathrm{ppm} \text { of HEDP } 50 \mathrm{ppm} \mathrm{ST}, \\
10 \mathrm{ppm} \mathrm{Zn}^{2+}\end{array}$ & $\begin{array}{c}\text { Well water } \mathrm{pH}= \\
8.38, \mathrm{Cl}^{-} 665 \\
\text { ppm }\end{array}$ & 54.02 & 98 & - & 51 \\
\hline Propargyl alcohol / 0.2-1.0 \% & $10 \% \mathrm{HCl}$ & 1.1 & 97 & - & 52,69 \\
\hline $\begin{array}{l}\text { Polyethylene-iminemethylene } \\
\text { phosphonic acid (PEIMPA) / } \\
500 \text { ppm }\end{array}$ & $1 \mathrm{M} \mathrm{HCl}$ & 0.160 & 90.11 & Langmuir & 53 \\
\hline $\begin{array}{l}\text { Propargyl alcohol (PA) and } \\
\text { potassium iodide (KI) / } 4 \mathrm{mM} \\
\text { PA }+4 \mathrm{mM} \mathrm{KI}\end{array}$ & $0.5 \mathrm{M} \mathrm{H}_{2} \mathrm{SO}_{4}$ & 35 & 95 & Langmuir & 54 \\
\hline $\begin{array}{l}\text { Mono-n-butyl phosphate (BP) } \\
\text { and mono-n-hexyl phosphate } \\
\text { (HP) / } 0.1 \mathrm{wt} \% \mathrm{BP} \text {, }\end{array}$ & $3.5 \% \mathrm{NaCl}$ & 10.68 & 92.6 & - & 62 \\
\hline $0.01 \mathrm{wt} \% \mathrm{HP}$ & & 60.10 & 58.3 & & \\
\hline $\begin{array}{l}\text { 2,5-bis(4-methoxyphenyl)-1,3,4- } \\
\text { oxadiazole (4-MOX) / } 0.8 \mathrm{mM}\end{array}$ & $0.5 \mathrm{M} \mathrm{H}_{2} \mathrm{SO}_{4}$ & - & 80.80 & Langmuir & 63 \\
\hline $\begin{array}{l}\text { 2-propargyl-5-o- } \\
\text { hydroxyphenyltetrazole (PHPT) } \\
\text { / } 5 \mathrm{mM}\end{array}$ & $\begin{array}{l}\text { Simulated } \\
\text { cooling water }\end{array}$ & 8 & 92 & - & 64 \\
\hline $\begin{array}{l}\text { 1H-benzo-imidazole } \\
\text { phenanthroline derivative / } 1 \\
\mathrm{mM}\end{array}$ & $1 \mathrm{M} \mathrm{HCl}$ & 2310 & 84.20 & Langmuir & 67 \\
\hline $\begin{array}{l}\text { Piperidin-1-yl-phosphonic acid } \\
\text { (PPA) / } 0.5 \mathrm{mM}\end{array}$ & $3 \% \mathrm{NaCl}$ & 252.8 & 76.70 & - & 68 \\
\hline $\begin{array}{l}\text { (4-phosphono-piperazin-1-yl) } \\
\text { phosphonic acid (PPPA) / } 0.5\end{array}$ & $3 \% \mathrm{NaCl}$ & 87.9 & 91.90 & - & 68 \\
\hline
\end{tabular}




\begin{tabular}{|c|c|c|c|c|c|}
\hline $\mathrm{mM}$ & & & & & \\
\hline $\begin{array}{l}\text { Polyethylene-iminemethylene } \\
\text { phosphonic acid (PEIMPA) / } \\
500 \text { ppm }\end{array}$ & $1 \mathrm{M} \mathrm{HCl}$ & 0.160 & 90.11 & Langmuir & 53 \\
\hline $\begin{array}{l}\text { 1-buthyl-3-methyl-1 } \mathrm{H} \text { - } \\
\text { benzimidazolium iodide / } 5 \mathrm{mM}\end{array}$ & $0.5 \mathrm{M} \mathrm{H}_{2} \mathrm{SO}_{4}$ & 83 & 98.7 & Langmuir & 69 \\
\hline $\begin{array}{l}\text { 4-(4-Aminophenyl- } \\
\text { thio)benzenamine / } 5 \mathrm{mM}\end{array}$ & $0.5 \mathrm{M} \mathrm{HCl}$ & 1660 & 90.1 & Langmuir & 70 \\
\hline Fluorophosphonic (FP) / $5 \mathrm{mM}$ & $0.1 \mathrm{M} \mathrm{NaClO}_{4}$ & 0.8 & 94.3 & - & 71 \\
\hline $\begin{array}{l}\text { Undecenyl-phosphonic acids } \\
\text { (UP) / } 5 \mathrm{mM}\end{array}$ & $0.1 \mathrm{M} \mathrm{NaClO}_{4}$ & 2 & 85.7 & - & 71 \\
\hline 4-methylpyrazole/ $5 \mathrm{mM}$ & $1 \mathrm{M} \mathrm{HCl}$ & 460.0 & 52.34 & Temkin & 72 \\
\hline $\mathrm{C} 8-\mathrm{D} / 4.6 \mathrm{mM}$ & $3.5 \% \mathrm{NaCl}$ & 5.42 & 93.89 & Langmuir & this work \\
\hline C12-D /4.6 mM & $3.5 \% \mathrm{NaCl}$ & 9.06 & 89.79 & Langmuir & this work \\
\hline
\end{tabular}

The IE of iron in $1 \mathrm{M} \mathrm{H}_{2} \mathrm{SO}_{4}$ solution in the presence of $4 \mathrm{mM}$ piperidin-1-yl-phosphonic acid (PPA) in 0.2-1.0\% propargyl alcohol in $15 \% \mathrm{HCl}$ was $91.38 \%$ [50] and $97 \%$ [69], respectively, close to C8-D $(93.89 \%)$. For iron immersed in $1 \mathrm{M} \mathrm{HCl}$ in the presence of 500 ppm PAIMA solution the reported $\mathrm{J}_{\text {corr }}$ $\left(0.302 \mathrm{~mA} . \mathrm{cm}^{-2}\right)$ is higher than those obtained for diphosphonic acids C8-D and C12-D and their inhibition efficiency (IE) is lower than those obtained for C8-D and C12-D [53]. In saline solution, C8-D and C4-D present higher inhibition efficiency and lower corrosion currents comparatively with mono-nbutyl phosphate (BP) and mono-n-hexyl phosphate (HP), piperidin-1-yl-phosphonic acid (PPA), (4phosphono-piperazin-1-yl)phosphonic acid (PPPA) or hydroxyethyl modified with oleic chain from coconut oil (HEI-M). These results confirm that a protective film was formed over the metal surface and hence retarded the corrosion reaction and suggest that the investigated phosphonic acids are good candidates for iron protection.

\section{Conclusions}

Herein, the effects of diphosphonate corrosion inhibitors with systematically different molecular size on carbon steel have been explored. These corrosion inhibitors (C1-D, C2-D, C4-D, C6-D, C8-D, and C12D) possess a common amino-methylenephosphonate $-\mathrm{N}^{+}(\mathrm{H})-\mathrm{CH}_{2}-\mathrm{PO}_{3} \mathrm{H}^{-}$zwitterionic moiety, but also 
a systematically elongated alkyl side-chain. XPS confirmed the interactions between the adsorbed inhibitor molecules and the metallic surface. Immersion of steel coupons in acidic solutions $(\mathrm{pH}=3.0)$ containing the inhibitors leads to additive adsorption on the steel surface via the phosphonate groups. The XPS results also suggest that these inhibitors exhibit significant deprotonation upon interaction with the carbon steel. The Fe $2 p$ spectra show metallic and oxidized iron for all samples studied. All additives achieve variable corrosion inhibition efficiencies (7-days at $\mathrm{pH}=2.0,3.0$ and 4.0 and inhibitor concentrations $0.01 \mathrm{mM}, 0.10 \mathrm{mM}$, and $1.00 \mathrm{mM})$.

The CP and EIS investigations in the presence of chloride ions produced the same results. A comparison between the diphosphonates gave the following observations:

(a) Lower corrosion resistance was obtained in the case of diphosphonate with short alkyl chains, such as C1-D, C2-D and C4-D. These inhibitors produce a thin, porous and/or incomplete layer on carbon steel surface. They apparently need longer times to diffuse to the surface and to provide a wellorganized layer.

(b) Longer alkyl chain molecules, such as C6-D, C8-D and C12-D are predisposed to accumulate at, and adsorb on the metallic surface more effectively, thus producing a more organized and thicker layer. The corrosion resistance of carbon steel in their presence is higher and the corrosion current is lower.

(c) The best results were obtained in the case of C8-D (lower corrosion current, higher $\mathrm{R}_{\mathrm{p}}$ and surface coverage). In the presence of this diphosphonic acid the CR was reduced by a factor of 6 .

The obtained experimental data were satisfactorily fitted with the Langmuir model. Short-chain diphosphonates demonstrate a less favorable adsorption process and that the formation rate of the protective layer on the metal interface is slower than in the long-chain inhibitors.

Supplementary Information. Crystallographic (cif) files for the compounds C1-D and C4-D, final Rietveld plots and hydrogen bonding interactions for compounds C1-D and C4-D, characterization of all 
diphosphonic acid corrosion inhibitors $\left({ }^{1} \mathrm{H},{ }^{13} \mathrm{C},{ }^{31} \mathrm{P}\right.$ NMR spectra, ART-IR spectra), corrosion specimen images, electrochemical data.

Corresponding Authors: * demadis@uoc.gr (KDD), andrew.g.thomas@manchester.ac.uk (AGT).

Author Contributions. The manuscript was written through contributions of all authors. All authors have given approval to the final version of the manuscript.

ACKNOWLEDGMENT. KDD thanks the Hellenic Foundation for Research and Innovation (HFRI) for financial support of the $\mathrm{PhD}$ Candidate Argyri Moschona, through a Research Fellowship (KA 10439). AGT wished to thank the School of Materials, University of Manchester for access to XPS instrumentation. AC and RMPC thank the Spanish MINECO support through the project MAT201677648-R. NP acknowledges the Institute of Chemistry Timisoara (Romanian Academy) for financial support (Program No. 2).

\section{REFERENCES}

(1) H.H. Uhlig and R.W. Revie, Corrosion and Corrosion Control, Wiley, New York, $3^{\text {rd }}$ Edn. 1985.

(2) D. Jones, Principles and Prevention of Corrosion", MacMillan Publishing Company, New York, 1992.

(3) L.M. Rivera-Grau, M. Casales, I. Regla, D.M. Ortega-Toledo, J.A.; Ascencio-Gutierrez, J. Porcayo-Calderon, L. Martinez-Gomez, Effect of organic corrosion inhibitors on the corrosion performance of 1018 carbon steel in $3 \% \mathrm{NaCl}$ solution, Int. J. Electrochem. Sci. 8 (2013) 24912503.

(4) G. Mu, X. Li, Q. Qu, J. Zhou, Molybdate and tungstate as corrosion inhibitors for cold rolling steel in hydrochloric acid solution, Corrosion Sci. 48 (2006) 445-459.

(5) C. Lai, B. Xie, L. Zou, X. Zheng, X. Ma, S. Zhu, Adsorption and corrosion inhibition of mild steel in hydrochloric acid solution by S-allyl-O,O'-dialkyldithiophosphates. Results in Physics 7 (2017) 3434-3443. 
(6) S.A. Umoren, M.M. Solomon, Synergistic corrosion inhibition effect of metal cations and mixtures of organic compounds: A Review. J. Env. Chem. Eng. 5 (2017) 246-273.

(7) A. Clearfield, K.D. Demadis, Metal phosphonate chemistry: From synthesis to applications. Royal Society of Chemistry, London, 2012, and references therein.

(8) K.D. Demadis, Chemistry of organophosphonate scale inhibitors. Part 4: Stability of amino-tris(methylene phosphonate) towards degradation by oxidizing biocides. Phosphorus Sulfur Silicon Relat. Elem. 181 (2006) 167-176.

(9) C. Yee, G. Kataby, A. Ulman, T. Prozorov, H. White, A. King, M. Rafailovich, J. Sokolov, A. Gedanken, Self-assembled monolayers of alkanesulfonic and -phosphonic acids on amorphous iron oxide nanoparticles. Langmuir 15 (1999) 7111-7115.

(10) D.-J. Choi, S.-J. You, J.-G. Kim, Development of an environmentally safe corrosion, scale, and microorganism inhibitor for open recirculating cooling systems. Mater. Sci. Eng.: A 335 (2002) 228-235.

(11) K.E. Papathanasiou, K.D. Demadis, Phosphonates in Matrices, in: Tailored Organic-Inorganic Materials, E. Brunet, A. Clearfield, J.L. Colon (Eds.), John Wiley \& Sons Inc.: 2015, Chapter 3, pp. 83-135.

(12) K.D. Demadis, S.D. Katarachia, M. Koutmos, Crystal growth and characterization of zinc(amino-tris(methylenephosphonate)) organic-inorganic hybrid networks and their inhibiting effect on metallic corrosion. Inorg. Chem. Comm. 8 (2005) 254-258.

(13) K.D. Demadis, C. Mantzaridis, R.G. Raptis, G. Mezei, Metal-organotetraphosphonate inorganic-organic hybrids: Crystal structure and anticorrosion effects of zinc-(hexamethylenediaminetetrakis(methylene phosphonate)) on carbon steels. Inorg. Chem. 44 (2005) 4469-4471.

(14) K.D. Demadis, M. Papadaki, R.G. Raptis, H. Zhao, 2D and 3D alkaline earth metal carboxyphosphonate hybrids: Anti-corrosion coatings for metal surfaces. J. Solid State Chem. 181 (2008) 679-683. 
K.D. Demadis, M. Papadaki, R.G. Raptis, H. Zhao, Corrugated, sheet-like architectures in layered alkaline earth metal R,S-hydroxyphosphonoacetate frameworks: Applications for anticorrosion protection of metal surfaces. Chem. Mater. 20 (2008) 4835-4846.

(16) J. Zon, P. Garczarek, M. Bialek, Synthesis of phosphonic acids and their esters as possible substrates for reticular chemistry, in Metal phosphonate chemistry: From synthesis to applications, A. Clearfield, K.D. Demadis (Editors). Royal Society of Chemistry, London, 2012, Chapter 6, pp. 170-191.

(17) R. Laamari, J. Benzakour, F. Berrekhis, A. Abouelfida, A. Derja, D. Villemin, Corrosion inhibition of carbon steel in hydrochloric acid $0.5 \mathrm{M}$ by hexamethylenediaminetetramethylphosphonic acid. Arabian J. Chem. 4 (2011) 271-277.

(18) S. Zhao, Y. Chen, B. Liu, M. Chen, J. Mao, H. He, Y. Zhao, N. Huang, G. Wan, A dual-task design of corrosion-controlling and osteo-compatible hexamethylenediaminetetrakis- (methylene phosphonic acid) (HDTMPA) coating on magnesium for biodegradable bone implants application. J. Biomed. Mater. Res. Part A, 103A (2015)1640-1652.

K. Kavipriya, J. Sathiyabama, S. Rajendran, R. Nagalakshmi, R. The inhibitive effect of diethylenetriaminepentamethylenephosphonic acid on the corrosion of carbon steel in sea water. Eur. Chem. Bull. 2 (2013) 423-429.

(20) N. Labjar, M. Lebrini, F. Bentiss, N.-E. Chihib, S. El Hajjaji, C. Jama, Corrosion inhibition of carbon steel and antibacterial properties of aminotris-(methylenephosphonic) acid. Mater. Chem. Phys. 119 (2010) 330-336.

(21) J.L. Fang, Y. Li, X.R. Ye, Z.W. Wang, Q. Liu, Passive films and corrosion protection due to phosphonic acid inhibitors. Corrosion 49 (1993) 266-271.

(22) N.V. Tsirulnikova, Y.V. Bolt, E.S. Dernovaya, B.N. Driker, T.S. Fetisova, Creation and study of formulations as inhibitors of metal corrosion and scaling for stabilization water treatment in water utilization systems (a review). Int. J. Corros. Scale Inhib. 5 (2016) 66-86. 
(23) K. Moedritzer, R.R. Irani, The direct synthesis of $\alpha$-aminomethylphosphonic acids. Mannichtype reactions with orthophosphorous acid. J. Org. Chem. 31 (1966) 1603-1607.

(24) J. Mao, Z. Wang, A. Clearfield, Synthesis, characterization, and crystal structure of two divalent metal disposponates with a layered and a 3D network structure. Inorg.Chem. 41 (2002) 23342340.

(25) M.F. Mady, M.A. Kelland, Overview of the synthesis of salts of organophosphonic acids and their application to the management of oilfield scale. Energy Fuels 31 (2017) 4603-4615.

(26) A. Altomare, C. Cuocci, C. Giacovazzo, A. Moliterni, R. Rizzi, N. Corriero, A. Falcicchio, EXPO2013: a kit of tools for phasing crystal structures from powder data. J. Appl. Crystallogr. 46 (2013) 1231-1235.

(27) E. Matczak-Jon, B. Kurzak, A. Kamecka, W. Sawka-Dobrowolska, P. Kafarski, Interactions of zinc(II), magnesium(II) and calcium(II) with iminodimethylenediphosphonic acids in aqueous solutions. J. Chem. Soc., Dalton Trans. (1999) 3627-3637.

(28) H.M. Rietveld, A profile refinement method for nuclear and magnetic structures, J. Appl. Crystallogr. 2 (1969) 65-71.

(29) A.C. Larson, R.B. von Dreele, General structure analysis system (GSAS) Report No. LA-UR2000, 86-748.

(30) B.H. Toby, EXPGUI, a graphical user interface for GSAS, J. Appl. Crystallogr. 34 (2001) 210213.

(31) N. Fairley, CasaXPS Manual 2.3.15 Introduction to XPS and AES, Casa Software, (2009).

(32) M.S. Walczak, P. Morales-Gil, T. Belashehr, K. Kousar, P. Arellanes Lozada, R. Lindsay, Determining the chemical composition of corrosion inhibitor/metal interfaces with XPS: Minimizing post immersion oxidation. J. Vis. Exp. 121 (2017) e55163, doi:10.3791/55163.

(33) P. Morales-Gil, M.S. Walczak, C.R. Camargo, R.A. Cottis, J.M. Romero, R. Lindsay, Corrosion inhibition of carbon-steel with 2-mercaptobenzimidazole in hydrochloric acid. Corrosion Sci. 101 (2015) 47-55. 

ing in an acidic medium: Interaction of 2-mercaptobenzimidazole with carbon-steel in hydrochloric acid. Corrosion Sci. 85 (2014) 109-114.

NACE Standard TM0169-95 (Item No. 21200), National Association of Corrosion Engineers, Houston TX, U.S.A. (www.nace.org).

(36) K.D. Demadis, E. Barouda, N. Stavgianoudaki, H. Zhao, Inorganic-organic hybrid molecular "ribbons" based on chelating/bridging, "pincer" tetraphosphonates and alkaline-earth metals. Cryst. Growth Des. 9 (2009) 1250-1253.

R. Vivani, F. Costantino, M. Nocchetti, G.D. Gatta, Structural homologies in benzylamino-N,Nbis methylphosphonic acid and its layered zirconium derivative. J. Solid State Chem. 177 (2004) 4013-4022.

(38) K.D. Demadis, E. Barouda, H. Zhao, R.G. Raptis, Structural architectures of charge-assisted, hydrogen-bonded, 2D layered amine $\cdots$ tetraphosphonate and zinc $\cdots$ tetraphosphonate ionic materials. Polyhedron 28 (2009) 3361-3367.

B.I. Makaranets, T.N. Polynova, V.K. Bel'skii, S.A. Ii'ichev, M.A. Porai-Koshits Crystal and molecular structure of ethylaminodimethylenephosphonic acid. J. Struct. Chem. 26 (1985) 761765.

(40) A. Moschona, N. Plesu, G. Mezei, A.G. Thomas, K.D. Demadis, Corrosion protection of carbon steel by tetraphosphonates of systematically different molecular size. Corros. Sci. 145 (2018) $135-150$.

(41) D.C. Kothari, M.R. Nair, A.A. Rangawala, K.B. Lal, P.D. Prabhawalkar and P.M. Roale, XPS studies at various temperatures of nitrogen implanted 304 stainless steel. Nucl. Instrum. Methods Phys. Res. B. 7-8 (1985) 235-241.

(42) M. Textor, L. Ruiz, R. Hofer, A. Rossi, K. Feldman, G. Hä̈ner, N.D. Spencer, Structural chemistry of self-assembled monolayers of octadecylphosphoric acid on tantalum oxide surfaces. Langmuir 16 (2000) 3257-3271. 

experimental investigation of the adsorption of a phosphonic acid on the anatase $\mathrm{TiO}_{2}(101)$ surface. J. Phys. Chem. C 120 (2016) 1693-1700.

(44) D. Briggs, M.P. Seah, Practical surface analysis (Second Edition), Volume 1 (Auger and X-ray Photoelectron Spectroscopy), John Wiley and Sons Ltd, Chichester, 1990.

M.C. Biesinger, B.P. Payne, A.P. Grosvenor, L.W.M. Lau, A.R. Gerson, R.S.C. Smart, Resolving surface chemical states in XPS analysis of first row transition metals, oxides and hydroxides: Cr, Mn, Fe, Co and Ni. Appl. Surf. Sci. 257 (2011) 2717-2730.

(46) A.P. Grosvenor, B.A. Kobe, M.C. Biesinger, M.S. McIntyre, Investigation of multiplet splitting of Fe 2p XPS spectra and bonding in iron compounds. Surf. Interf. Anal. 36 (2004) 1564-1574.

(47) G.C. Smith, Evaluation of a simple correction for the hydrocarbon contamination layer in quantitative surface analysis by XPS, J. Electron Spectrosc. 148 (2005) 21-28.

(48) J. Balajka, M.A. Hines, W.J.I. DeBenedetti, M. Komora, J. Pavelec, M. Schmid, U. Diebold, High-affinity adsorption leads to molecularly ordered interfaces on $\mathrm{TiO}_{2}$ in air and solution. Science 361 (2018) 786-789.

(49) M.W. Khalil, Anodic Tafel behaviour of mild steel in presence of inhibitors. Materialwiss Werkst. 23 (1992) 111-115.

(50) A. Nithya, S. Rajendran, A Critical review of corrosion inhibition by phosphonic acids. Bulg. Chem. Commun. 42 (2010) 119-125.

(51) S.A. Kanimozhi, S. Rajendran, Inhibitive properties of sodium tungstate- $\mathrm{Zn}^{2+}$ system and its synergism with HEDP. Int. J. Electrochem. Sci. 4 (2009) 353-368.

(52) M. Bartos N. Hackerman, A Study of inhibition action of propargyl alcohol during anodic dissolution of iron in hydrochloric acid. J. Electrochem. Soc. 139 (1992) 3428-3433.

(53) M. Salah, L. Lahcene, A. Omar, H. Yahia, Study of corrosion inhibition of C38 steel in $1 \mathrm{M}$ $\mathrm{HCl}$ solution by polyethyleneiminemethylene phosphonic acid, Int. J. Ind. Chem. 8 (2017) 263272. 
Y. Feng, K.S. Siow, W.K. Teo, A.K. Hseieh, The synergistic effects of propargyl alcohol and potassium iodide on the inhibition of mild steel in $0.5 \mathrm{M}$ sulfuric acid solution. Corros. Sci. 41 (1999) 829-852.

R.N. Devi, P. Wormald, P.A. Cox and P.A. Wright, Novel pillared aluminum ethylene diphosphonate displaying reversible dehydration-rehydration behavior, Chem.Mater. 16 (2004) 22292237.

(56) M. Chen, Y.Chen, W. Zhang, S. Zhao, J. Wang, J. Mao, W. Li, Y. Zhao, N. Huang, G. Wan, Controlling corrosion rate and behavior of biodegradable magnesium by surface-immobilized ultra thin 1-hydroxyethylidene-1,1-diphosphonic acid (HEDP) film. RSC Adv. 18 (2016) 1443915278.

(57) K.D. Demadis, P. Lykoudis, R.G. Raptis, G. Mezei, Phosphonopolycarboxylates as chemical additives for calcite scale dissolution and metallic corrosion inhibition based on a calciumphosphonotricarboxylate organic-inorganic hybrid. Cryst. Growth Des. 6 (2006) 1064-1067.

B. Stuart. Infrared Spectroscopy: Fundamentals and Applications. John Wiley \& Sons, Ltd. 2004 p. 84 .

(59) I. Gouzman, M. Dubey, M.D. Carolus, J. Schwartz, S.L. Bernasek, Monolayer vs. multilayer self-assembled alkylphosphonate films: X-ray photoelectron spectroscopy studies. Surf. Sci. 600 (2006) 773-781.

(60) R.O. Snyder, H.L. Strauss, C-H stretching modes and the structure of n-alkyl chains. 1. Long, disordered chains. J. Phys. Chem. 86 (1982) 5145-5150.

(61) G.M. Kosolapoff, Chemistry of aliphatic phosphonic Acids. II. Dielectric constants and viscosity of some higher alkylphosphonates, 5 (1953) 615-617.

(62) C. Zhao, X. Gao, H. Lu, C. Wang, R. Yan, H. Ma, Spontaneous formation of mono-n-butyl phosphate and mono-n-hexyl phosphate thin films on the iron surface in aqueous solution and their corrosion protection property. RSC Adv. 5 (2015) 54420-54432. 

methoxyphenyl)-1,3,4-oxadiazole as a corrosion inhibitor for mild steel in normal sulfuric acid medium. Corros. Sci. 48 (2006) 2831-2842.

(64) N. Dkhireche, A. Dahami, A. Rochdi, J. Hmimou, R. Touir, M. Ebn Touhami, M. El Bakri, A. El Hallaoui, A. Anouar, H. Takenouti, Corrosion and scale inhibition of low carbon steel in cooling water system by 2-propargyl-5-o-hydroxyphenyltetrazole. Mat. Chem. Phys. 122 (2010) 1-9.

(65) K. Kavipriya, S. Rajendran, J. Sathiyabama, A. S. Prabha, A critical review of corrosion inhibition by phosphonic acids. Eur. Chem. Bull. 1 (2012) 366-374.

(66) L.D. Mall, V.C. Srivastava, N.K. Agrawal, I.M. Mishra, Adsorptive removal of malachite green dye from aqueous solution by bagasse fly ash and activated carbon-kinetic study and equilibrium isotherm analyses. Colloids Surf. A: Physicochem. Eng. Aspects. 264 (2005) 17-28.

(67) X. Lei, H. Wang, Y. Feng, J. Zhang, X. Sun, S. Lai, Z. Wang, S. Kang, Synthesis, evaluation and thermodynamics of a $1 \mathrm{H}$-benzo-imidazole phenanthroline derivative as a novel inhibitor for mild steel against acidic corrosion. RSC Adv. 5 (2015) 99084-99094.

(68) H. Amar, J. Benzakour, A. Derja, D. Villemin, B. Moreau, A corrosion inhibition study of iron by phosphonic acids in sodium chloride solution, J. Electroanal. Chem. 558 (2003) 131-139.

(69) X. Zheng, S. Zhang, W. Li, L. Yin, J. He, J. Wu, Investigation of 1-butyl-3-methyl -1Hbenzimidazolium iodide as inhibitor for mild steel in sulfuric acid solution. Corros Sci. 80 (2014)383-392.

(70) N. K. Bakirhan, A. Asan, N. Colak, S. Sanli, The Inhibition Of Steel Corrosion In Acidic Solutions By A New Schiff Base, J. Chil. Chem. Soc. 61 ( 2016) 3066-3070.

(71) T. Abohalkuma , J. Telegdi, Corrosion protection of carbon steel by special phosphonic acid nano-layers, Mater. Corros. 66 (2015) 1382-1390.

(72) K.F. Khaled, S.S. Abdel-Rehim, G.B. Sakr, On the corrosion inhibition of iron in hydrochloric acid solutions, Part I: Electrochemical DC and AC studies, Arab. J. Chem. 5 (2012) 213-218. 
Table of Contents artwork

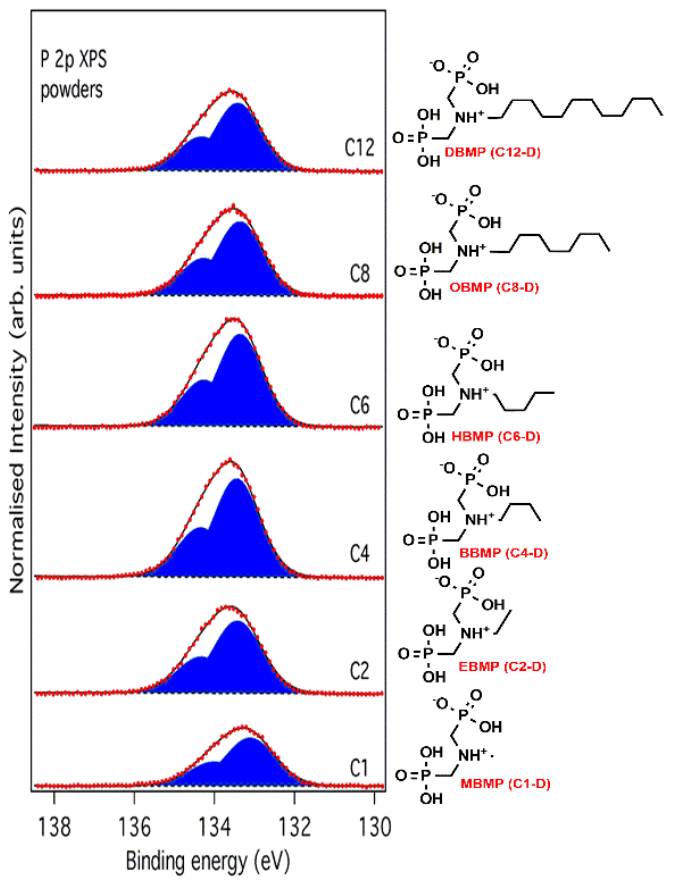

